\section{PROCESOS DE GENTRIFICACIÓN Y CONTRAGENTRIFICACIÓN. LOS MERCADOS DE ABASTO Y DEL NORTE EN EL GRAN SAN MIGUEL DE TUCUMÁN (NOROESTE ARGENTINO)'}

Paula Luciana Boldrini² ${ }^{2}$ Matilde Malizia ${ }^{3}$

\section{Resumen}

Bajo la influencia de dinámicas propias de la globalización, como la mercantilización creciente del espacio urbano y la proliferación de nuevas formas de producción inmobiliaria, las ciudades latinoamericanas se transforman mediante nuevas dinámicas sociales y espaciales. Una de ellas es la rehabilitación y puesta en valor de áreas urbanas deterioradas, consideradas como procesos de gentrificación, en los que se configuran nuevas expresiones territoriales, políticas y económicas, así como diferentes tipos de luchas en defensa del territorio, constituyendo su contracara, la contragentrificación.

Se busca analizar si los procesos de cambio socioespacial en dos mercados localizados en el centro

\section{GENTRIFICATION AND COUNTER-GENTRIFICATION PROCESSES. THE ABASTO AND NORTHERN MARKETS IN GRAN SAN MIGUEL DE TUCUMAN (NORTHWESTERN ARGENTINA) ${ }^{1}$}

Paula Luciana Boldrini² ${ }^{2}$ Matilde Malizia ${ }^{3}$

\section{Abstract}

The influence of globalization-related dynamics such as the growing commodification of urban space and the emergence of new forms of real estate production has resulted in cities being transformed through new social and spatial mechanics. One of these forces is the rehabilitation and revaluation of deteriorated urban areas by means of a process known as gentrification, in which new territorial, political and economic expressions are configured. This process is also tied to struggles for the protection of the territory, which emerge as the other side of gentrification, namely counter-gentrification.

This paper analyzes the characteristics of the socio-spatial changes in two markets located in Gran San Miguel de Tucuman (Northwestern 
del aglomerado Gran San Miguel de Tucumán (NO Argentino), podrían enmarcarse como procesos de gentrificación, indagando a su vez en sus características particulares. Para ello se identifican las transformaciones socio-espaciales ocurridas en los mercados y su entorno inmediato, mediante el análisis del contexto urbano en el que surgieron y se desarrollaron; los cambios en el uso del suelo; y las perspectivas de los actores sociales intervinientes. De esta forma se cumple el objetivo propuesto y produce nuevo conocimiento vinculado a la cronología de sucesos característicos, constituyéndose como fases de desarrollo de los procesos de gentrificación.

\section{PALABRAS CLAVE: RENOVACIÓN URBANA GENTRIFICACIÓN, CONTRAGENTRIFICACIÓN}

Fecha de recepción: 30.05.13

Fecha de aceptación: 05.05.14

1 Este artículo forma parte de las investigaciones llevadas adelante en el marco del Proyecto "La Argentina fragmentada: territorios y sociedades en la primera década del siglo XXI". Consejo Nacional de Investigaciones Científicas y Técnicas (CONICET). PIP No 11220100100073. Dirigido por el Dr. Pablo Paolasso (Instituto Superior de Estudios Sociales, CONICET-UNT). Período 2011-2013.

2 Argentina. Arquitecta Universidad Nacional de Tucumán. Magister en Psicología Social Universidad Nacional de Tucumán. Doctora en Ciencias Sociales (orientación Geografía) Universidad Nacional de Tucumán. Becaria posdoctoral Consejo Nacional de Investigaciones Científicas y Técnicas CONICET. Correo electrónico: paula_boldrini@hotmail.com

3 Argentina. Licenciada en Trabajo Social Universidad Nacional de Tucumán. Doctora en Ciencias Sociales (orientación Geografía) Universidad Nacional de Tucumán.. Becaria posdoctoral Consejo Nacional de Investigaciones Científicas y Técnicas CONICET. Correo electrónico: matumalizia@yahoo.com.ar
Argentina) and whether these transformations fit within the category of gentrification. To do so, the different socio-spatial changes in these markets and their surroundings are identified through the analysis of changes in the use of land, the perspectives of social actors and the urban context that saw the emergence and development of these transformations. In this way, the objective of this research is accomplished and new knowledge related to the chronology of these events is produced; thus emerging as development phases within gentrification processes.

\section{KEYWORDS: URBAN RENEWAL, GENTRIFICATION, COUNTER-GENTRIFICATION}

\author{
Received: 30.05.13
}

Accepted: 05.05.14

1 This paper is part of research conducted within the framework of the Project "Fragmented Argentina: Territories and Societies During the First Decade of the XXI Century". National Council on Scientific and Technical Research (CONICET). PIP N ${ }^{\circ}$ 11220100100073. This research was supervised by Pablo Paolasso, PhD (Higher Institute of Social Studies, CONICET - UNT), 2011-2013.

2 Argentina. Architect, National University of Tucuman. MSc in Social Psychology, National University of Tucuman. PhD in Social Sciences (Geography-oriented), National University of Tucuman. Post-doctoral fellow, National Council on Scientific and Technical Research, CONICET. Email: paula_boldrini@hotmail.com

3 Argentina. BA in Social Work, National University of Tucuman. PhD in Social Sciences (Geography-oriented), National University of Tucuman. Post-doctoral fellow, National Council on Scientific and Technical Research, CONICET. Email: matumalizia@yahoo.com.ar 


\section{Introducción}

Las ciudades de América Latina que se pensaban ante todo como lugares donde se conjugaban el progreso y la modernidad han pasado, en las últimas décadas, por un proceso de diferenciación en su estructura espacial y social como resultado de la combinación de complejos factores relacionados con el avance del capitalismo global y con patrones culturales, históricos y sociales ${ }^{4}$. Estas urbes son el territorio ${ }^{5}$ donde múltiples procesos, vinculados con la globalización y las políticas neoliberales actuales $^{6}$, adquieren un carácter concreto y localizado, un espacio donde se materializan fuertes

4 Ciccolella, 2012; Prévôt Schapira, 2002.

5 Se entiende por territorio a las interacciones entre la sociedad y el medio natural a través del tiempo. La cultura actúa como mediadora en las relaciones entre la sociedad y la naturaleza, impulsando una manera particular de valorar los recursos y con ello un tipo particular de economía (Sauer, 1941:15).

6 Mientras el neoliberalismo representó una estrategia política, social y económica, es decir la apropiación por un grupo del poder social en sentido amplio, la globalización constituyó un componente económico-geográfico que constituyó una nueva variante del capitalismo erosionando las fronteras económicas establecidas por el sistema de Estados nacionales, haciendo difícil identificar economías nacionales separadas unas de otras (Smith, 2008). contradicciones ${ }^{7}$. La apariencia que adquiere cada ciudad y la manera como ésta organiza y utiliza sus espacios constituyen la base material sobre la cual se desarrollan las prácticas sociales, prácticas que a su vez influyen en el desarrollo y expansión de la ciudad, generando de este modo un proceso complejo de retroalimentación ${ }^{8}$.

Bajo la influencia de dinámicas propias de la globalización, como la mercantilización creciente del espacio urbano y la proliferación de nuevas formas de producción inmobiliaria, entre otros aspectos, las grandes ciudades latinoamericanas comenzaron a modificar no sólo sus políticas urbanas, sino también su organización, funcionamiento, morfología y apariencia ${ }^{9}$. Un aspecto central de estas nuevas políticas urbanas son las reglas, regulaciones, programas y micro políticas que, desde una perspectiva puramente económica, ponen a la ciudad en valor. Como resultado de la aplicación

7 Sassen, 2007; Mertins, 2003. La aplicación de las políticas neoliberales se manifiesta en una paulatina contracción del Estado, transformación del mercado laboral, disminución de la primacía de las principales ciudades, consecuente aumento de la población urbana en ciudades intermedias y aumento de la informalidad del mercado de tierras y viviendas, entre otras cosas (Portes, Roberts, Grimson y Aliaga, 2005).

8 Harvey, 1998.

9 Janoschka, 2011; Mattos, 2009; Sabatini, 2008. 
de estas políticas se generan nuevas dinámicas sociales y espaciales, que no descartan las anteriores sino que por el contrario las incorporan y actualizan e impactan en los centros y/o edificios históricos mediante diversos procesos como la gentrificación ${ }^{10}$

Así es como la gentrificación, siguiendo a Janoschka $^{11}$, se puede considerar un mecanismo cada vez más intenso y central propio de la época contemporánea del capitalismo avanzado y globalizado. En este sentido, diferentes términos como rehabilitación, revitalización o renovación urbana suelen esconder, detrás de un discurso eufemístico y propagandístico, la creciente mercantilización de las ciudades y la profundización y perpetuación de las diferencias sociales a escala territorial.

10 Less, Slater y Wyly, 2007. El término fue acuñado por Ruth Glass en el año 1964 para describir la expulsión de los arrendatarios de clase obrera de los barrios históricos de Londres a favor de habitantes de clase media quienes, a su vez, ya sea por cuenta propia o mediante una inversión privada introducían renovaciones (Salinas Arreortua, 2013; Janoschka y Casgrain, 2010).

11 Janoschka, 2011.
Las ciudades tienden a satisfacer cada vez más las necesidades de consumidores con elevado poder adquisitivo, en detrimento de los ciudadanos con menos recursos y poder adquisitivo.

En el transcurso de las últimas décadas del siglo XX se identificaron en las ciudades latinoamericanas, procesos de rehabilitación urbana y puesta en valor de áreas deterioradas que podrían ser considerados como procesos de gentrificación propiamente dichos ${ }^{12}$. No obstante, su desarrollo sostenido recién comenzó a partir de la década del '90 influyendo tanto en áreas centrales como periféricas $^{13}$. Durante este periodo las transformaciones económicas impactaron en las ciudades reforzando la relación entre lo local y lo global ${ }^{14}$. El Estado disminuyó su intervención directa sobre el territorio

12 Di Virgilio, Lanzetta, Redondo y Rodríguez, 2000; Jones y Varley citado en Janoschka y Casgrain, 2010 fueron los primeros en introducir el término gentrificación en América Latina al analizar los procesos de conservación en el centro de la ciudad de Puebla, en México.

13 Este tipo de procesos fueron descriptos para ciudades como Santiago de Chile (Álvarez, 2010), Bogotá (Urbina González, 2012) y México (Salinas Arreortua, 2013), entre otras. En Argentina, los casos emblemáticos de gentrificación ocurrieron en los barrios de Palermo (Carbajal, 2003), La Boca (Di Virgilio, Lanzetta, Redondo y Rodríguez, 2000), Puerto Madero (Lienur, 2001) y Mercado de Abasto, todos en Buenos Aires.

14 Este nuevo orden, que conecta lo global con lo local, es un sistema dinámico, expansivo y excluyente de sectores sociales, territorios y países, socava el Estado de Bienestar, induce a una crisis institucional y pondera la competitividad a través de una línea simplista y auto-destructiva de atracción de inversores a cualquier precio (Borja y Castells, 1998; Bayardo y Lacarrieu, 1999). 
al asumir un rol de facilitador y promotor de la inversión privada ${ }^{15}$. Sin embargo Janoschka ${ }^{16}$ explica que cuando los procesos de gentrificación se extienden a los países latinoamericanos encarnan nuevas expresiones territoriales, nuevas relaciones políticas y económicas y diferentes tipos de luchas en defensa del territorio.

En Argentina, a partir del año 2003 se está desarrollando un nuevo escenario político definido por algunos autores como neodesarrollismo ${ }^{17}$. Este nuevo contexto se origina a partir de la crisis nacional que devino en significativos conflictos sociales en el año 2001, momento en el que se instala un nuevo gobierno que propone un nuevo rol por parte del Estado. Éste procura recuperar su carácter activo al operar en forma explícita sobre cuestiones que en la década del '90 eran promovidas predominantemente desde el mercado. Se originan

15 Ciccolella, 1999

16 Janoschka, 2011.

17 Katz, 2006; Svampa, 2008, Féliz, 2011. El modelo basado en la sustitución de importaciones se conoce como desarrollismo. Según Katz (2006) en la actualidad se habla de un modelo "neo" y no plenamente desarrollista porque preserva la restricción monetaria, el ajuste fiscal, la prioridad exportadora y la concentración del ingreso. Apunta a incrementar los subsidios estatales a la industria para revertir las consecuencias del libre comercio extremo. nuevas políticas en materia territorial ${ }^{18}$ mediante programas de hábitat y proyectos habitacionales que, en algunos casos, combinaron soluciones urbanas y de vivienda con la generación de empleo generando permanencias, reapropiaciones y novedades con un reconocimiento implícito (y muchas veces explícito) de la existencia de un movimiento social reconfigurado y con una importante capacidad de confrontación y resistencia ${ }^{19}$. Se trata, en materia de hábitat, de un escenario propicio para la investigación de continuidades, transformaciones y rupturas.

Es en este sentido que este artículo busca analizar si los procesos de cambio socio-espacial que están aconteciendo en los mercados de Abasto y del Norte y su área de influencia inmediata, localizados en el centro del aglomerado Gran San Miguel de Tucumán (GSMT), podrían enmarcarse en los denominados procesos de gentrificación ${ }^{20}$, indagando a su vez en sus características particulares. Para

18 La última década evidencia una nueva respuesta estatal a las demandas sociales ligadas al problema urbano, como la recientemente aprobada ley de hábitat popular en la provincia de Buenos Aires, el proyecto de Ley de Hábitat Digno en Tucumán, entre otras. Estas medidas expresan, a diferentes escalas, la respuesta a antiguas demandas sostenidas por sectores populares e intelectuales de la sociedad.

19 Féliz, 2011.

20 Son escasos los estudios que analizan en profundidad el impacto y las particularidades de las transformaciones urbanas ocurridas en los últimos años en el aglomerado Gran San Miguel de Tucumán (Malizia, 2011; Malizia y Paolasso, 2009; Mertins, 2003/2004)

revista invi № 81 / Agosto 2014 / Volumen № 29: 157-191 161 
ello se identificarán las transformaciones socioespaciales ocurridas en el área que contiene a cada uno de los mercados, así como los cambios acontecidos al interior de ellos. Estas transformaciones expresan el interés de ciertos sectores, tanto públicos como privados (promotores inmobiliarios y el Estado provincial y municipal) por desarrollar procesos de renovación del espacio urbano. Los procesos de cambio y renovación de barrios históricos identificados como gentrificación, son uno de los fenómenos más actuales de los últimos veinte años en algunas ciudades argentinas ${ }^{21}$, por lo cual son aun incipientemente estudiados.

\section{El análisis de la gentrificación: su proceso de estudio}

Se entiende por gentrificación a los procesos de renovación de viejos centros urbanos mediante transformaciones materiales (edilicias) e inmateriales (económicas, sociales y culturales) conducidas por agentes privados y/o públicos, provocando la subida del valor de las propiedades y el consiguiente

21 Carbajal, 2003. desplazamiento y/o sustitución, directo e indirecto, de la población residente por otros grupos sociales con poder adquisitivo más elevado ${ }^{22}$.

Administradores provinciales y municipales y agentes inmobiliarios buscan instalar sobre la ciudad tradicional la imagen de la ciudad posmoderna. Los viejos edificios son rehabilitados, restaurados y lanzados en el mercado para un público dotado de un capital financiero y cultural adecuado. Como expresa Bataller ${ }^{23}$ el desplazamiento de la población residente va acompañado de inversiones y mejoras tanto en las viviendas, que son renovadas o rehabilitadas, como en toda el área afectada, abarcando los comercios, el equipamiento y los servicios. Esto implica necesariamente cambios en el mercado del suelo y de la vivienda otorgando un papel decisivo a los agentes inmobiliarios. Las áreas gentrificadas son construidas como islas de bienestar y constituyen el motor de la capacidad competitiva de la ciudad en el mercado globaliza$\mathrm{do}^{24}$, en tanto se configuran como focos de atracción para el consumo.

El móvil principal que conduce a la ejecución de un proceso de gentrificación, es la ganancia que se especula obtener a través del cambio en el valor del suelo

22 Janoschka, 2011; García Herrera, 2001; Bataller, 2000. Su etimología deriva del término inglés gentry (personas que por su nivel social sólo están por debajo de la nobleza) que significa aburguesamiento (Tella, 2005)

23 Bataller, 2000.

24 Améndola, 2000. 
entre la fase de deterioro y su posterior revalorización, es decir lo que se denomina diferencia potencial de la renta o rent gap ${ }^{25}$. Esto implica un incremento de los precios de la vivienda a raíz de una especulación inmobiliaria que acentúa y precipita una transformación social en detrimento de los grupos que tradicionalmente vivían y utilizaban estos espacios.

El deterioro urbano y edilicio y la consecuente desvalorización del barrio tiende a considerarse, entonces, como el requisito fundamental para la aparición de este proceso. A su vez, la revalorización del barrio puede proceder tanto de planes de rehabilitación propuestos por el Estado como por el desarrollo de emprendimientos a cargo de agentes inmobiliarios en el centro y/o alrededores de los barrios que se quieren gentrificar provocando cambios en el valor del suelo. Su desarrollo, por lo general, se produce a lo largo de muchos años; y sus principales consecuencias conllevan cambios en el mercado de la vivienda, entre los que se destaca el aumento del

25 Díaz Parra, 2004. La rent gap “consiste en dar un uso más lucrativo al suelo poniendo en peligro el activo, que deteriorado pierde valor en el mercado", en donde el "activo" es el espacio gentrificable y se reconoce más por la oferta que por la demanda de dicho espacio (Urbina González, 2012: 43).

ARTíCULO: Procesos de gentrificación y contragentrificación. Los mercados de Abasto y del Norte en el Gran San Miguel de Tucumán (noroeste argentino) / Paula Luciana Boldrini, Matilde Malizia precio de la propiedad renovada y no renovada, la disminución de la densidad de población en el área afectada, la transformación progresiva de la modalidad de ocupación y el desplazamiento, directo o indirecto, de sus habitantes tradicionales ${ }^{26}$.

Por otra parte, el proceso de gentrificación puede encontrar movimientos de resistencia entre los grupos sociales desplazados, directa o indirectamente, de las áreas sujetas a este tipo de renovación urbana. Leite ${ }^{27}$ denomina a este proceso antinobrecimiento, un término que según Janoschka y Casgrain ${ }^{28}$ podría traducirse como contragentrificación o de-gentrificación. Este tipo de protestas podrían desacelerar los procesos de gentrificación a través de nuevos enfoques y experiencias populares, y expresan una lucha contra las actuales condiciones de acumulación capitalista. Se expresan por lo general, mediante movimientos sociales progresistas como el conocido "derecho a la ciudad"29. Para los autores estas protestas podrían ser

26 Sabatini, Sarella Robles y Vásquez (2009, p. 18-19) proponen el término "gentrificación sin expulsión". Los procesos de gentrificación en Latinoamérica "se vinculan pero, a la vez, se diferencian de los procesos y tendencias que se registran en ciudades de países desarrollados, peculiaridades que obedecen a las fuerzas y actores específicos que están transformando el patrón tradicional de segregación de la ciudad latinoamericana".

27 Leite citado en Janoschka y Casgrain, 2010.

28 Janoschka y Casgrain, 2010.

29 En España existe una plataforma para la defensa de los mercados de abasto, considerados como espacios de intercambio comercial iniciados antiguamente en las plazas públicas y que, actualmente, llevan implícito el espíritu de sitio de reunión [En línea: http://mercadodeabastos.wordpress.com].

revista invi № 81 / Agosto 2014 / Volumen № 29: 157-191 163 
el mecanismo para revertir los procesos de gentrificación en curso en muchas ciudades latinoamericanas.

Para estudiar, entonces, el desarrollo de un proceso de gentrificación es pertinente analizar, desde una perspectiva de corte neoliberal, diversas características que ponen de manifiesto este proceso en las ciudades latinoamericanas ${ }^{30}$. Dichas características se refieren a:

- Localización próxima al centro comercial y financiero de la ciudad.

- Dotación de servicios de infraestructura provenientes de red pública.

- Imagen urbana consolidada y lugares asociados a la memoria colectiva: poseen una identidad propia en la que permanecen vigentes patrones urbanos locales particulares ${ }^{31}$.

- Áreas deterioradas: implica la degradación o desvalorización del barrio.

- Reinversión de capital, principalmente extranjero, en un espacio definido.

- Cambios en el uso funcional de los edificios con el objetivo de implantar nuevas funciones comerciales en ese sector: contempla la construcción de hoteles internacionales, centros

30 Janoschka, 2011; Less, Slater y Wyly, 2007; Améndola, 2000; Bataller, 2000; Zukin, 1996.

31 En definitiva, como explica Harvey (1998), se convierten en centros de consumo cultural que transforman paulatinamente la historia en mercancía. comerciales, shopping centers e incluso urbanizaciones cerradas.

- Desplazamiento, directo o indirecto, de la población local y su sustitución progresiva por otros grupos sociales con ingresos elevados.

Las fuentes de información utilizadas para abordar el problema planteado son el resultado de la aplicación de técnicas de investigación cualitativa (análisis de documentos bibliográficos, fotográficos y cartográficos ${ }^{32}$, entrevistas cortas y/o conversaciones informales ${ }^{33}$ y observación con participación ${ }^{34}$ ), aplicadas durante el primer trimestre del año 2013. Estas fuentes, dado su nivel de profundización, permitieron identificar y verificar si las características esenciales para que un proceso de gentrificación se desarrolle, se cumplían en los casos estudiados.

El análisis de documentos bibliográficos, fotográficos y cartográficos (provenientes de la Municipalidad de San Miguel de Tucumán, la Dirección Provincial de Estadística y de la Comisión de Patrimonio Cultural de la Provincia) permitió conocer, analizar y contextualizar los principales procesos socio-espaciales que acontecieron en el área de estudio y que dieron lugar al desarrollo de procesos

\footnotetext{
32 Yuni y Urbano, 2003.

33 Taylor y Bogdan, 1990.

34 Guber, 2009.
} 
de gentrificación, estableciendo relaciones entre acontecimientos pasados, presentes y futuros. También se trabajó con notas periodísticas publicadas por diferentes medios, principalmente por los diarios La Gaceta -el matutino más importante de la provincia- y Contrapunto -el periódico local más relevante de prensa alternativa-.

Asimismo, durante el transcurso del trabajo de campo se mantuvieron entrevistas cortas y/o conversaciones informales con distintas personas que aportaron información valiosa y complementaria sobre la temática ${ }^{35}$. La interacción con los interlocutores a través de estos encuentros permitió comprender el sentido y significado de los cambios ocurridos en torno a los mercados y su contexto inmediato, sobre todo durante las últimas décadas.

La observación con participación, por su parte, posibilitó detectar los contextos y situaciones en los cuales se expresan y generan los universos culturales y sociales en torno a la gentrificación. Esta herramienta permitió la construcción de datos en virtud de un proceso reflexivo entre investigador e interlocutores. Mediante esta técnica se observó y registró sistemáticamente lo que acontecía en el campo en torno a los mercados en estudio.

35 Este tipo de entrevistas y/o conversaciones surgieron de manera espontánea durante los recorridos y fueron realizadas a vuelo de pájaro.
La presentación de los resultados se organizó en tres apartados cuyo análisis se desarrolló en forma progresiva. El primero se refiere al contexto urbano y social en el que surgieron y se desarrollaron los casos en estudio, teniendo en cuenta el proceso de expansión urbana y entendiendo que estas áreas son espacios socialmente reconocidos por los habitantes del aglomerado. Asimismo en este apartado se indagan las perspectivas de los actores sociales intervinientes (vecinos, trabajadores, usuarios, empresas privadas ${ }^{36}$ y Municipalidad de San Miguel de Tucumán ${ }^{37}$ ), teniendo en cuenta los intereses que guían su accionar. En el segundo apartado se analizan, desde una perspectiva funcional (material), los cambios que se producen gradualmente en el uso del suelo tanto en el área inmediata que contienen a ambos mercados como en su interior. En este artículo el área inmediata está constituida por los edificios circundantes que lindan o se localizan alrededor de ambos mercados. En el último apartado se elabora una síntesis de los resultados en la que se resaltan los principales aportes. Contiene la verificación de los aspectos centrales de la gentrificación en los casos analizados y la caracterización de las cinco fases identificadas en el aglomerado GSMT que podrían

36 No ha sido posible establecer ningún tipo de contacto con las empresas privadas involucradas en los procesos de gentrificación estudiados dado que son empresas "fantasmas", es decir que no cuentan con una dirección específica donde ubicarlas.

37 Se realizaron reiterados intentos por entrevistar a personal de la Municipalidad, sin embargo el resultado fue siempre negativo. 
FIGURA 1. UBICACIÓN DE LOS MERCADOS DE ABASTO Y DEL NORTE EN EL AGLOMERADO GRAN SAN MIGUEL DE TUCUMÁN

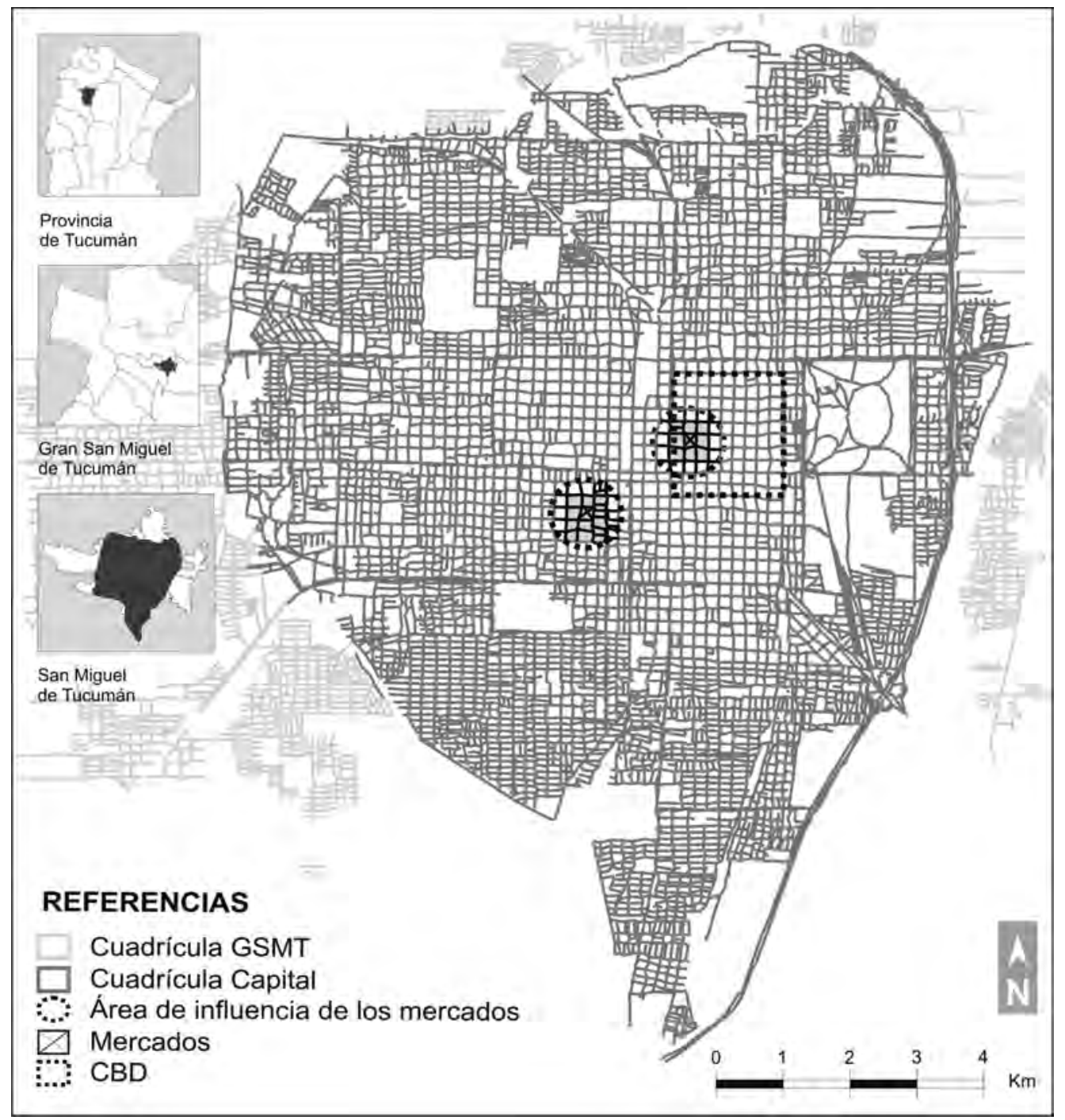

Fuente. Dirección Provincial de Estadística, 2001; Municipalidad de San Miguel de Tucumán, 2008.

166 revista invi № 81 / Agosto 2014 / Volumen № 29: 157-191 
ser susceptibles de aplicarse en ciudades con atributos similares.

\section{Los casos: Mercado de Abasto y Mercado del Norte}

Los mercados de Abasto y del Norte se encuentran localizados en la centro del aglomerado GSMT, en el Municipio San Miguel de Tucumán (Figura 1) ${ }^{38}$. En la actualidad más del 95\% de la superficie total de este Municipio se encuentra urbanizada y además, al estar rodeado de otras localidades y comunas cuyas áreas de contacto también lo están, no cuenta con territorio hacia el cual expandirse ${ }^{39}$. Por lo tanto la sustitución de funciones de tipo comercial/comercial y residencial/comercial, de espacios ya existentes, parece ser la única opción para su crecimiento y desarrollo.

Los patrones que condujeron los cambios tanto en el área central como en la periferia del aglomerado, se consolidaron y reforzaron a lo largo de las últimas décadas junto con el surgimiento, en forma simultánea, de nuevos caracteres que definen a la

38 Este aglomerado, en el noroeste de Argentina, es considerado en la jerarquía urbana nacional, como una ciudad intermedia (Jordan y Simioni, 1998; Vapñarsky, 1994 y 1995). El aglomerado GSMT, con sus 824.000 habitantes (EPH, segundo trimestre 2012) junto con el Gran Mendoza y el Gran La Plata son las principales ciudades intermedias del país.

39 Gómez López, Cuozzo y Boldrini, 2012; Malizia y Boldrini, en prensa. ciudad actual, dando lugar a procesos de segregación y fragmentación socio-espacial renovados. En el centro del aglomerado se está produciendo un remplazo gradual de las viviendas unifamiliares por edificios en altura orientados hacia el mismo grupo social que vivía anteriormente en la zona (grupos con poder adquisitivo medio y medio alto) y hacia familias del mismo sector que residía en los márgenes de la ciudad ${ }^{40}$. En este sentido, recién en los últimos años comenzaron a gestarse procesos de renovación urbana que consisten, siguiendo a Mertins ${ }^{41}$, en un cambio de uso del suelo que incluye casi siempre la reurbanización y gentrificación suntuosa de áreas céntricas. Se trata, del paso de viviendas unifamiliares a edificios en altura, y de una función que combina actividades residenciales y comerciales a una función eminentemente comercial. Es justamente allí, en el área central del aglomerado, donde es posible identificar transformaciones urbanas que podrían definirse como procesos de gentrificación. 


\section{Mercado de Abasto}

En el año 1927 el arquitecto Alberto Prebisch diseñó el Mercado de Abasto combinando elementos de la arquitectura moderna y colonial. Lo construyó sobre una hectárea localizada en la periferia del casco urbano tradicional e histórico de la ciudad de San Miguel de Tucumán (en el tradicional barrio La Ciudadela) ${ }^{42}$. Fue inaugurado en el año 1934 como el principal mercado central en el que se concentraba la venta mayorista y minorista de frutas, verduras y productos aviarios, entre otros.

Posteriormente, en el transcurso de la década del '60, el edificio del mercado quedó integrado al área de expansión de la ciudad, pero siempre afuera del Central Business District (CBD). Ya en ese momento, los urbanistas señalaban que el mercado no podría continuar funcionando por mucho tiempo más en su localización original dado que "...la aldea de 1934 se había transformado, tres décadas más tarde, en una ciudad tan pujante que no toleraba el tráfico mayorista frutihortícola a un puñado de cuadras de la plaza Independencia [la plaza principal de la ciudad]"43.

42 A principios del siglo XX la ciudad se asentaba sobre una cuadrícula de nueve por nueve manzanas cuyo centro era la plaza principal. El Mercado de Abasto estaba ubicado hacia el sureste, en la entonces periferia urbana.

43 Diario La Gaceta, 2012.
Por ese motivo, en el año 1969 se decidió trasladar al Mercado de Abasto a un predio ubicado en la nueva periferia de la ciudad capitalina, sin embargo, esto recién se concretó a fines de la década ' $90^{44}$. Las intensas deliberaciones entre los puesteros durante ese periodo provocaron que no todos optaran por trasladarse al nuevo predio y en su lugar muchos de ellos decidieron instalar sus puestos sobre las calles laterales que rodeaban al mercado. Un vendedor de diarios que trabaja en la zona hace más de veinte años explica: “... adentro [del Mercado de Abasto] quedaron algunos puesteros y después sólo una familia viviendo, y después sacaron todo y quedó abandonado unos tres años hasta que empezaron a construir [el nuevo emprendimiento comerciall" (D., vendedor de diarios, 8/02/13). Como consecuencia del cierre del mercado, el edificio quedó abandonado y en estado de deterioro por aproximadamente cuatro años hasta que comenzaron las obras de construcción de un nuevo emprendimiento comercial.

Hasta la fecha en que el Mercado de Abasto cerró sus puertas, la zona se caracterizaba por el desarrollo de actividades comerciales complementarias al mismo, destinadas sobre todo a un grupo social con ingresos medio-bajo; por la localización sobre

44 En el año 1998 se inauguró el Mercado de Concentración Frutihortícola de Tucumán (Mercofrut), el cual concentra, principalmente, la venta mayorista y minorista (sólo los días sábado) de frutas y hortalizas. 
su calle lateral norte de la Facultad de Ciencias Naturales e Instituto Miguel Lillo ${ }^{45}$ que trajo aparejado la instalación de residencias estudiantiles en toda el área; y por la presencia de familias tradicionales que han vivido allí desde los inicios del barrio. La convivencia de funciones comerciales, educativas y residenciales le otorgaba a la zona una imagen urbana particular y consolidada.

\section{Mercado del Norte}

Este mercado fue inaugurado en el año 1939, no obstante sus instalaciones fueron construidas en la década de 1880 sobre el terreno que ocupada el antiguo Mercado del Algarrobo desde mediados del siglo XIX. Esta situación en la actualidad le imprime al edificio del mercado un elevado valor histórico, arquitectónico, cultural y patrimonial, "la impronta original se mantiene a pesar del paso de los años, y es esta característica la que brinda al mercado ese aire pintoresco"46.

A diferencia del caso anterior, este mercado se encuentra integrado al CBD principal del aglomerado,

45 En el año 1933 la Universidad Nacional de Tucumán crea el Instituto Miguel Lillo cuyo objetivo principal era el estudio de las ciencias naturales. En el año 1953 se crea la Escuela Universitaria de Ciencias Naturales, y recién en 1984 se las unifica creando una sola estructura académica, la Facultad de Ciencias Naturales e Instituto Miguel Lillo [En línea: http://www.unt.edu.ar/ archivos/files/pdfs/parte_ii.pdf].

Diario Contrapunto, 13/12/2008. en una zona de convergencia peatonal y vehicular. De esta manera el tránsito, tanto al interior como en sus alrededores, es constante e intenso durante los días hábiles. Surgió como un mercado principalmente minorista que concentraba a 250 puesteros. Allí no sólo se podían adquirir diversos tipos de productos frutihortícolas, aviarios y vacunos, sino que además contaba con bares al paso en los que se podía ordenar desde comidas regionales hasta platos elaborados. "Era el sitio donde se concentraban una cantidad de proveedores y de actividades comerciales en competencia entre sí, por eso había tantos puestos, para que no fuera un monopolio sino un verdadero mercado..."47.

En la actualidad sólo quedan 83 puestos funcionando que han tenido que adaptarse a los requerimientos comerciales vigentes para mantenerse como uno de los principales centros de abastecimiento minorista destinado, sobre todo, a los sectores medio-bajo y bajo. Tal como lo describe un periódico local de prensa alternativa “... Constituye el principal centro de compras de abastecimiento para los tucumanos y cumple una función socialmente importante, no sólo para aquellas

47 Un gigante en la ciudad [videograbación] producido por la Escuela de Video, Cine y TV. Universidad Nacional de Tucumán, 2010 En línea: http://www.youtube.com/watch?v=6CN3hr40qhE.

revista invi Nº 81 / Agosto 2014 / Volumen № 29: 157-191 169 
personas que trabajan en él, sino también para todos aquellos que buscan bajos precios" ${ }^{\prime \prime 8}$.

El área que rodea al Mercado del Norte se caracteriza por la presencia de locales comerciales que, si bien no dependen directamente del mercado, se comportan como negocios satélites al mismo. Así también sobre sus calles laterales se ubican puestos de venta informal y galerías comerciales que nuclean a algunos vendedores ambulantes que han sido relocalizados, pese a que aún muchos de ellos continúan trabajando en la calle. Este tipo de oferta comercial le imprime a la zona una particularidad que la diferencia del resto del CBD, otorgándole una identidad consolidada en la cual permanecen vigentes, aspectos que la diferencian del resto de la ciudad. Por último es posible advertir la presencia de edificios residenciales en altura cuyos habitantes pertenecen a grupos con mediano poder adquisitivo

\section{Presentación de los resultados}

Tal como se explicó anteriormente, la presentación de los resultados estará organizada en tres apartados interrelacionados. El primero hace referencia

48 Diario Contrapunto, 2008.

170 revista invi № 81 / Agosto 2014 / Volumen № 29: 157-191 al contexto urbano y social en el que surgieron y se desarrollaron los mercados de Abasto y del Norte y se indagan las perspectivas de los actores sociales intervinientes; en el segundo se analizan desde una perspectiva funcional, los cambios en el uso del suelo de ambos mercados y sus alrededores, y en el último, se elabora una síntesis de los resultados en la que se verifican los aspectos centrales de la gentrificación en los casos de estudio y se caracterizan, en forma teórica, las fases identificadas.

\section{CONTEXTO URBANO Y SOCIAL}

Las áreas que contienen a los mercados estudiados presentan distintas condiciones urbanas caracterizadas por aspectos morfológicos y arquitectónicos, por su devenir histórico y por el nivel de cobertura de infraestructura. Estos aspectos fueron analizados cronológicamente y organizados en diferentes fases que permiten identificar momentos en el proceso de transformación urbana (Tabla 1).

Cuando se inauguraron ambos mercados el paisaje urbano que los rodeaba, estaba configurado por calles coloniales con una edificación continua sobre la línea municipal. Las principales viviendas eran las casas chorizo ${ }^{49}$, cuyos detalles arquitectónicos denotaban mayor poder adquisitivo a medida que se aproximaban al centro. En sus alrededores

49 La casa chorizo es un tipo de vivienda típica que consiste en un patio lateral al que dan las habitaciones dispuestas en hilera y conectadas entre sí (Gregorio, 2006).

ARTíCULO: Procesos de gentrificación y contragentrificación. Los mercados de Abasto y de Norte en el Gran San Miguel de Tucumán (noroeste argentino) / Paula Luciana Boldrini, 
TABLA 1. FASES IDENTIFICADAS EN EL PROCESO DE GENTRIFICACIÓN EN EL AGLOMERADO GRAN SAN MIGUEL DE TUCUMÁN Y SUS CARACTERÍSTICAS EN LOS MERCADOS DE ABASTO Y DEL NORTE

\begin{tabular}{|c|c|c|c|}
\hline FASES & NOMBRE & MERCADO DE ABASTO & MERCADO DEL NORTE \\
\hline F. 1 & $\begin{array}{l}\text { Deterioro } \\
\text { urbano }\end{array}$ & \multicolumn{2}{|c|}{$\begin{array}{l}\text { El deterioro urbano del edificio y su entorno es aprovechado por el Estado y las empresas } \\
\text { privadas para impulsar la sustitución de la actividad principal, por otra de carácter global }\end{array}$} \\
\hline & $\begin{array}{l}\text { Formulación } \\
\text { de proyectos } \\
\text { comerciales }\end{array}$ & \multicolumn{2}{|c|}{$\begin{array}{l}\text { Se elabora un moderno proyecto comercial cuyo diseño reproduce una imagen urbana y } \\
\text { arquitectónica dominante, que implica el desplazamiento de los puesteros y los pequeños } \\
\text { comerciantes tradicionales de la zona }\end{array}$} \\
\hline F. 2 & Impacto & $\begin{array}{l}\text { Los esfuerzos de los puesteros fueron infructuo- } \\
\text { sos y son desalojados. Algunos son relocalizados } \\
\text { en un nuevo mercado a las afueras de la ciudad } \\
\text { (Mercofrut) }\end{array}$ & $\begin{array}{l}\text { Surge una organización de puesteros } \\
\text { que detiene la ejecución del proyecto. } \\
\text { Se establecen acuerdos entre los } \\
\text { puesteros y el Municipio para mejorar } \\
\text { el edificio }\end{array}$ \\
\hline F. 3 & Transición & $\begin{array}{l}\text { Se cierra el mercado y se lo traslada a la periferia } \\
\text { de la ciudad. Los comercios y viviendas se fueron } \\
\text { cerrando progresivamente hasta ser reemplaza- } \\
\text { dos por bares y discotecas que le imprimieron a la } \\
\text { zona un nuevo sesgo. Comienzan las obras en el } \\
\text { predio del mercado }\end{array}$ & $\begin{array}{l}\text { Se incrementa el deterioro del edificio. } \\
\text { Se producen sucesivas actividades } \\
\text { de resistencia por parte de puesteros, } \\
\text { vecinos y diferentes sectores de la } \\
\text { comunidad. Se llevan a cabo intensas } \\
\text { negociaciones entre la cooperativa de } \\
\text { puesteros y el Municipio capitalino }\end{array}$ \\
\hline \multirow[t]{2}{*}{ F. 4} & $\begin{array}{l}\text { Materialización } \\
\text { de los cambios }\end{array}$ & \multicolumn{2}{|l|}{$\begin{array}{l}\text { El Municipio desaloja a los puesteros instalados } \\
\text { sobre las calles aledañas y clausura bares y dis- } \\
\text { cotecas. Las obras de construcción llevadas a } \\
\text { cabo en el predio del mercado están prácticamen- } \\
\text { te finalizadas }\end{array}$} \\
\hline & Impacto & \multicolumn{2}{|l|}{$\begin{array}{l}\text { Avanza el abandono del área por parte de familias } \\
\text { y trabajadores tradicionales de la zona }\end{array}$} \\
\hline F. 5 & $\begin{array}{l}\text { Funcionamiento } \\
\text { y adaptación } \\
\text { del entorno }\end{array}$ & \multicolumn{2}{|l|}{$\begin{array}{l}\text { En noviembre de } 2012 \text { se inauguraron parte de } \\
\text { las instalaciones del nuevo emprendimiento. El } \\
\text { Estado municipal prevé el cambio de las carac- } \\
\text { terísticas comerciales de la zona mediante la in- } \\
\text { troducción de comercios de lujo. Descontento de } \\
\text { vecinos, comerciantes y ex trabajadores }\end{array}$} \\
\hline
\end{tabular}

Fuente: Trabajo de campo de las autoras, 2013. 
se alojaban edificios de gran singularidad, monumentos nacionales y valiosos exponentes arquitectónicos ${ }^{50}$. Sus calles estaban adoquinadas y contaban con los servicios de infraestructura básicos ${ }^{51}$. Esta homogeneidad morfológica y fisonómica, que se mantuvo con énfasis hasta mediados del siglo $\mathrm{XX}^{52}$, ha ido desapareciendo en forma paulatina en las últimas décadas ${ }^{53}$.

El área de influencia de ambos mercados era eminentemente comercial. Esta situación les otorgaba una imagen urbana particular que los diferenciaba del resto de la ciudad. Vecinos y trabajadores recuerdan el funcionamiento de los mercados: "Yo compraba la verdura ahí [haciendo referencia al Mercado de Abasto]” (V. vecina, 08/02/2013), “... venían muchas camionetas y salían todas cargadas con productos frescos para vender..." (A., vendedor ambulante, 08/02/2013), "...cuando el mercado trabajaba venía mucha gente porque vendían carnes, pescados y verduras" (C., vecina, 08/02/2013).

50 SPDUA, 2002.

51 La infraestructura básica hace referencia a la ejecución de obras destinadas a la distribución de personas, bienes e información, así como a la extracción y transformación de los insumos básicos de energía y agua. [En línea: http://www.vision2030.gob. $\mathrm{mx} / \mathrm{pdf} / 15$ analisis/ECYGDE_INFRAESTRUCTURA.pdf].

52 Bomba, Caminos, Casares y Di Lullo, 2007.

53 Los mercados y su entorno se han deteriorado progresivamente. Este deterioro se encuentra estrechamente vinculado a la falta de intervención estatal en tanto no hubo una dotación sensible de recursos destinados a contribuir al mejoramiento de la zona. La ausencia relativa del Estado hace suponer que el interés gentrificador ya estaba presente desde hace algunas décadas.

172 revista invi № 81 / Agosto 2014 / Volumen No 29: 157-191
De este modo se identificó en el proceso de transformación urbana una primera fase caracterizada por el deterioro urbano progresivo que forma parte, incluso, de la identidad del área. En esta etapa, la vida cotidiana entre vecinos, usuarios, comerciantes, trabajadores del mercado y el Estado Municipal $^{54}$ se desarrollaba de manera armónica. A pesar que ya existían en esa época demandas por mejoras edilicias, el desarrollo de las actividades comerciales sostenía activa la dinámica de los mercados.

La segunda fase se centra en la formulación de proyectos comerciales para estos sitios ${ }^{55}$. Dichos proyectos conducen a la sustitución de la actividad tradicional del área, caracterizada por el uso público del espacio, por otra actividad también comercial pero con un uso del espacio es privado o semi-privado en tanto comprenden cierto grado de control ${ }^{56}$ sobre sus usuarios. El establecimiento previsto es el resultado de un estrecho convenio

54 La Municipalidad de San Miguel de Tucumán, es propietaria de predio y del edificio del mercado, y concesiona a comerciantes privados la explotación de los puestos.

55 La Ley Provincial 7535 sancionada en el año 2005 declara como patrimonio cultural, histórico y arquitectónico de Tucumán a los edificios de ambos mercados. Establece que cualquier proyecto de modificación de estos edificios debe contar con la aprobación de la Comisión de Patrimonio Cultural de la provincia, preservar ambos edificios y asegurar la confluencia de actividades culturales con emprendimientos comerciales.

56 Este control suele ejercerse mediante los tipos de productos que se venden y sus precios, restringiendo de esta manera el consumo, y por lo tanto el uso del espacio, a sectores con poder adquisitivo.

ARTíCULO: Procesos de gentrificación y contragentrificación. Los mercados de Abasto y del Norte en el Gran San Miguel de Tucumán (noroeste argentino) / Paula Luciana Boldrini, 
entre una empresa privada y el Estado Municipal. Así es que a fines de los años '90, con el objetivo de remodelar y reutilizar los edificios de ambos mercados, se diseñaron modernos centros comerciales que reproducen una imagen urbana y arquitectónica dominante (cuya matriz se repite indistintamente en muchas ciudades latinoamericanas) y que desplazan a los puesteros y a los pequeños comerciantes de sus alrededores.

Las empresas privadas involucradas son compañías internacionales que han llevado a cabo la ejecución de proyectos similares en distintas ciudades de América Latina. Las reformas iniciadas en el ex Mercado de Abasto estuvieron conducidas inicialmente por la empresa nacional Abasto S.A. la cual, luego de diversos desacuerdos políticos-económicos, fue sustituida por otra agencia nacional, Vizora Desarrollos Inmobiliarios. Esta se basa en dos grandes ejes, uno gestiona de manera integral nuevos proyectos de diversa envergadura abarcando diseño, dirección, management, comercialización, marketing y financiamiento; mientras que el otro implica el cambio de imagen, remodelación y reforma de proyectos ya existentes. Por su parte, la empresa promotora del proyecto en el Mercado del Norte es el Grupo Empresarial Inversiones y Representaciones S. A. (IRSA). Este grupo ha desarrollado diversos emprendimientos inmobiliarios cuya gestión incluye la adquisición de propiedades para la construcción de edificios de oficinas y centros comerciales, la sustitución de funciones residenciales en áreas centrales por hoteles de lujo, la inversión inmobiliaria de activos extranjeros y las reservas de tierra en zonas estratégicas de la ciudad. En ambos casos, estas empresas centran su interés en la reproducción del capital financiero a partir de la concepción de la tierra como bien de cambio y no como bien de uso ${ }^{57}$. El fin es obtener una ganancia a partir del cambio de función urbana, es decir se prioriza la rent gap, dejando de lado los intereses de la comunidad en general.

Como resultado en el Mercado de Abasto, luego de intensas negociaciones entre el Municipio y la empresa constructora, se decidió construir un centro comercial y un hotel de lujo, mientras que en el Mercado del Norte se planeó la edificación de un centro comercial En esta etapa la situación de la comunidad en ambos mercados (vecinos, usuarios, comerciantes y trabajadores) estuvo marcada fundamentalmente por la confusión, basada en la desinformación. En ningún caso existieron comunicados oficiales que pusieran en discusión los nuevos proyectos, sino por el contrario, se iniciaban y consolidaban las estrategias del municipio orientadas a la desvinculación de los contratos de concesión. Se vislumbraba implícitamente la idea de vaciamiento por parte del Estado Municipal, buscando generar las condiciones necesarias para la implantación de la nueva actividad.

57 Lefebvre, 1973 
A partir de esta instancia, el derrotero por el que transitaron ambos mercados se dividió, dando lugar a una tercera fase considerada de transición. En el Mercado de Abasto esta etapa comenzó a fines de los noventa y se mantuvo durante toda la década de 2000. Si bien habían cesado las actividades en el mercado debido a su cierre definitivo, la instalación de algunos puesteros sobre sus calles aledañas, sosteniendo de manera activa el comercio frutihortícola, mantuvo por algunos años la identidad comercial de la zona. En forma simultánea parte de los comercios y viviendas que caracterizaban la función urbana del barrio se cerraron progresivamente hasta ser reemplazados por bares y discotecas que le imprimieron un nuevo sesgo a la zona del Abasto. Al respecto unas vecinas opinaban "... antes la zona era tranquila, los negocios adentro y las familias afuera, pero después ya no podían habitarlas [a las viviendas] porque se hicieron los boliches [locales bailables]" (C., vecina, 8/02/2013), "la gente era buena... pero después en la época de los boliches la zona se vino abajo" (P., vecina, 8/02/2013). Estos

174 revista invi № 81 / Agosto 2014 / Volumen N ํ2: 157-191 relatos ponen en evidencia la incompatibilidad que existía entre los locales de esparcimiento nocturno y la vida cotidiana de los habitantes del barrio. Esta situación alteró la dinámica familiar dejando calles desoladas durante el día y problemas crecientes de inseguridad durante la noche ${ }^{58}$. Asimismo durante esta etapa comenzaron las obras de construcción en el ahora denominado ex Mercado de Abasto. La demolición de más de la mitad del edificio original ${ }^{59}$, enmarcada en un proyecto de renovación urbana, dio lugar al desarrollo de un irreversible proceso de gentrificación.

La intempestiva instalación de los locales bailables contribuyó al desmantelamiento definitivo del sistema de actividades que giraba alrededor del funcionamiento del mercado. Si los vecinos del barrio acuñaban alguna expectativa de mejora vinculada al sostenimiento de la vieja dinámica barrial, esta quedaba sepultada con el conflictivo funcionamiento de una actividad que promovió el abandono de muchas de las viviendas y negocios familiares.

58 Es conocido nacionalmente el caso de Paulina Lebbos, quien luego de concurrir a los locales bailables de la zona del Abasto en febrero de 2006 desapareció y fue encontrada sin vida dos semanas después a un costado de un camino vecinal. El caso aun no se ha esclarecido.

59 En abril de 2007, en el marco del proyecto de renovación del mercado, se derribó sin autorización de la Comisión de Patrimonio Cultural de la Provincia parte del edificio. Ante esta irregularidad esta comisión ordenó reformular el proyecto para incluir la restauración y conservación de lo que quedaba del edificio.

ARTíCULO: Procesos de gentrificación y contragentrificación. Los mercados de Abasto y de Norte en el Gran San Miguel de Tucumán (noroeste argentino) / Paula Luciana Boldrini, 
En el Mercado del Norte, en cambio, la etapa de transición recién comenzó en la década del 2000. Esta se caracterizó por el incremento del deterioro edilicio, las sucesivas actividades de resistencia llevadas adelante por puesteros, vecinos y diferentes sectores de la comunidad, y por las intensas negociaciones entre los puesteros ${ }^{60}$ y el Municipio capitalino. La movilización y gestión de los puesteros originó acuerdos y compromisos entre las partes involucradas que estarían destinados a dar continuidad a la actividad tradicional del mercado ${ }^{61}$. Sin embargo el incumplimiento de estos acuerdos redundó en la profundización del deterioro edilicio que, a su vez, incrementó la falta de higiene y salubridad; y en el abandono de locales y su posterior demolición por parte del Municipio. Estas situaciones aumentaron las condiciones de vulnerabilidad de los puesteros poniendo en riesgo la continuidad de su actividad laboral y reanimaron el fantasma de la llegada de una empresa privada que socavaría sus puestos de trabajo. Un puestero explicaba "... si hay alguien que no puede seguir, lo cierran al puesto, no lo licitan, nada [...] cuando cierran los derrumban

60 Entre los años 1991 y 1998 el mercado fue administrado por la Cooperativa Mercado del Norte Limitada (CoMeNor) integrada por sus puesteros.

61 La Ordenanza Provincial 2815 otorgaba a los puesteros la concesión del mercado por siete años con el compromiso de ejecutar obras de mantenimiento, mientras que la Secretaría de Planeamiento Urbano se comprometía a elaborar un proyecto para mejorar el edificio, lo cual no se concretó y en 2008 los puesteros recibieron una intimación de desalojo. para que no pueda venir nadie [...]. Cuantos más puestos puedan derrumbar [la Municipalidad] mejor para ellos, ellos siguen cerrando todo lo que pueden" (J., puestero, 22/02/2013). Esta etapa de tensión permanente e intereses contrapuestos desembocó en un proceso de contragentrificación que se mantiene hasta la actualidad ${ }^{62}$.

Con el afán de evitar que esta situación se repita en el Mercado del Norte la comunidad lleva adelante diversos mecanismos de resistencia (movilizaciones, notas periodísticas y documentales, entre otros) en pos de detener el proceso de renovación urbana propuesto, "...se trata de un proceso de resistencia a la economía globalizada [...]. El mercado es un espacio de cultura local y popular. [...] no solo se perjudicarán los trabajadores del mercado, sino una inmensa cantidad de negocios satélites al mercado"63, "...la Municipalidad nunca dio apoyo para mejorar el lugar [...] tenemos hasta Mayo, y después habrá que luchar" (M., puestero, 22/02/2013). La clave para detener momentáneamente el proceso de gentrificación en curso y construir un proceso de contragentrificación es, principalmente, el con-

62 En 2009 la Comisión de Patrimonio Cultural de la Provincia decretó que se respete este edificio y su actividad comercial fortaleciendo, de esta manera, la posición de los puesteros.

63 Un gigante en la ciudad [videograbación] producido por la Escuela de Video, Cine y TV. Universidad Nacional de Tucumán, 2010. En línea: http://www.youtube.com/watch?v=6CN3hr40qhE 
junto de acciones de resistencia llevadas adelante por los trabajadores del mercado organizados. Si bien hasta el momento en que emergió el conflicto existía una suerte de unión entre los puesteros, la necesidad de sostener su fuente de trabajo ante un inminente desalojo dio lugar a su organización y cohesión en forma sostenida en el tiempo. La consolidada integración que surgió entre los puesteros les permite mostrarse hacia afuera como un bloque. Asimismo la posibilidad que el conflicto sea capitalizado por la oposición al gobierno de turno contribuyó al apaciguamiento de las disputas y al éxito, provisorio, de los trabajadores del mercado.

Éstos además cuentan con el apoyo de amplios sectores de la comunidad (se reunieron más de 35.000 firmas en apoyo al sostenimiento de la actividad actual), entre ellos, grupos vinculados al ámbito académico que alientan la producción de trabajos reflexivos y concientizadores en torno al conflicto del mercado ${ }^{64}$. Las medidas de protesta son consideradas el único mecanismo capaz de impedir el cierre definitivo de las fuentes de trabajo y colocan a la comunidad en clara oposición al nuevo proyecto comercial. El mercado es considerado un emblema urbano que subsiste en un contexto avasallado por un modelo de ciudad homogeneizador y elitista.

64 Si bien hasta la fecha prevalece el proceso de contragentrificación, el vencimiento de los contratos de alquiler de los puestos a fines de mayo del presente año dará lugar a nuevas negociaciones.

176 revista invi № 81 / Agosto 2014 / Volumen N² 29: 157-191
El Estado Municipal, en cambio, recurre a diversos mecanismos disuasivos para favorecer la ejecución de los nuevos emprendimientos comerciales. Esto se evidencia en la ausencia de recursos destinados a mantener y mejorar los mercados y en las constantes presiones ejercidas sobre sus trabajadores, No obstante otro organismo provincial, la Comisión de Patrimonio Cultural de la Provincia, se opuso oportunamente (sin éxito) a la demolición del ex Mercado de Abasto y se opone actualmente al cambio de función del Mercado del Norte. Estas contradicciones dentro del poder público son las que vehiculizan las demandas populares y posibilitan su llegada a los medios de comunicación tendientes a sensibilizar la opinión pública.

Las siguientes fases (cuatro y cinco) se desarrollan de manera interrelacionada y corresponden a la efectiva materialización de los cambios en el uso del suelo y a la puesta en funcionamiento de sus instalaciones. Teniendo en cuenta el desarrollo de ambos mercados hasta esta instancia, sólo el Mercado de Abasto se encuentra atravesando dichas etapas. Durante la cuarta fase, que abarca un periodo relativamente corto, la Municipalidad de San Miguel de Tucumán llevó adelante una suerte de limpieza de la zona al desalojar a los puesteros que quedaban sobre sus calles aledañas y clausurar 
definitivamente a bares y discotecas. En forma simultánea las obras de construcción en el predio del mercado se encontraban prácticamente finalizadas.

Numerosos relatos confirman el cambio laboral atravesado por los puesteros y comerciantes de la zona así como la falta de información provista por el gobierno local. Los entrevistados sostienen diversas versiones, creen que el Estado indemnizó, relocalizó o simplemente desalojó a los puesteros: "... los trasladaron a un galpón a media cuadra pero no aguantaron porque ya no venía gente" (D., diarero, 08/02/2013) "... los que habian quedado adentro [del mercado] se fueron a trabajar a la calle San Lorenzo, pero hace poco los sacaron, les pagaron 10.000 pesos a cada uno" (C., vecina, 08/02/2013), “...ahora lamentablemente la gente se dedica a otra cosa como cortar el césped o a la construcción porque el Mercofrut nos queda a trasmano [...] y además nos arruina porque hay feria [minorista] los sábados" (A., verdulero ambulante, 08/02/2013). El proceso de gentrificación en curso aún no produjo un cambio socio-espacial que redunde en el mejoramiento de las condiciones de vida de los trabajadores, por el contrario desestructuró sus actividades productivas de subsistencia y los excluye de las actividades comerciales previstas para el área, "...esto nuevo es como un casino, es para la gente que tiene plata" (A., vendedor ambulante, 08/02/2013).
Por otra parte, la súbita aparición y cierre de bares y discotecas evidencia el manejo inmobiliario especulativo que el Estado en concordancia con las empresas privadas, hace del área. Una vecina explica lo sucedido: "... de los boliches queda uno sólo [...] y si subsiste debe ser porque tiene un buen contacto porque al resto los cepillaron a todos" (F., vecina, 08/02/2013). La clausura de estos espacios generó entre los vecinos una suerte de incertidumbre. A su vez los emprendimientos comerciales planificados para el área poco tienen que ver con las actividades tradicionales del barrio del Abasto. El titular del Ente de Turismo de la Provincia comentaba "...las características comerciales de la zona van a cambiar, de boliches y verdulerías a bares, restaurantes y marcas top" ${ }^{25}$.

Finalmente, la inauguración de las nuevas instalaciones en el ex Mercado de Abasto dieron lugar al desarrollo de la última fase que permanece vigente. La oferta comercial y de servicios (gastronómicos, culturales, comerciales y de esparcimiento) que brinda el nuevo emprendimiento, tiene por objetivo acercar a los usuarios la posibilidad de no abandonar el área en pos de satisfacer sus necesidades. La propaganda de este proyecto se apropia de la identidad y del valor patrimonial que anteriormente tenía la zona generando una isla

65 Diario La Gaceta, 2012. 


\section{FIGURA 2. USO DEL SUELO EN EL ÁREA DE INFLUENCIA DEL EX MERCADO DE ABASTO}

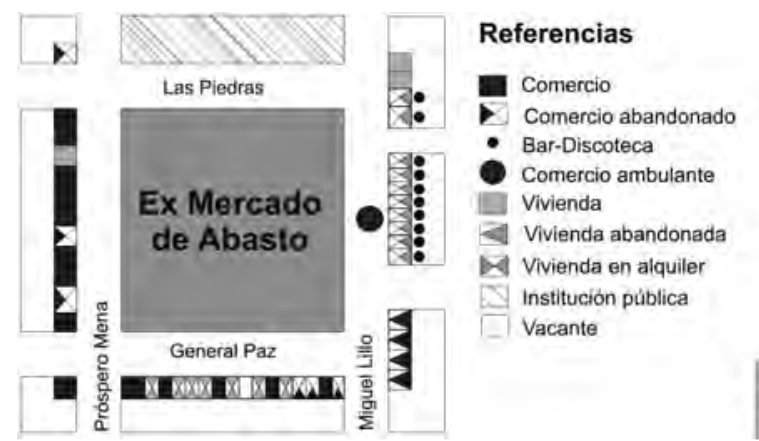

Fuente. Trabajo de campo de las autoras, 2013.

de consumo ${ }^{66}$. Su utilización está destinada a un grupo social con poder adquisitivo medio-alto y alto, dejando de lado a los tradicionales vecinos, comerciantes y ex trabajadores del mercado. No obstante, siete meses después de su inauguración no se perciben señales de mejora y crecimiento en el barrio, por el contrario, la cantidad de locales desocupados o en alquiler incrementan el aspec-

66 La implantación de este tipo de centros en distintas áreas de la ciudad resalta la tendencia hacia una ciudad segregada y dividida (Janoschka, 2002).

178 revista invi № 81 / Agosto 2014 / Volumen № 29: 157-191
TABLA 2. USO DEL SUELO EN EL ÁREA DE INFLUENCIA DEL EX MERCADO DE ABASTO

\begin{tabular}{|c|c|c|}
\hline & Total absoluto & Total en $\%$ \\
\hline Viviendas & 19 & 38,8 \\
\hline en uso & 3 & 6,1 \\
\hline abandonada & 9 & 18,4 \\
\hline en alquiler & 7 & 14,3 \\
\hline Comercios & 27 & 55,1 \\
\hline minoristas & 7 & 14,3 \\
\hline mayoristas & 8 & 16,3 \\
\hline abandonados & 12 & 24,5 \\
\hline Edificios público-privados & 1 & 2 \\
\hline institución pública & 1 & 2 \\
\hline Espacios disponibles & 2 & 4 \\
\hline vacantes & 2 & 4 \\
\hline Total & 49 & 100 \\
\hline
\end{tabular}

Fuente. Trabajo de campo de las autoras, 2013.

to desolado de la zona. Vecinos y comerciantes expresan "Pensábamos que iba a haber más movimiento [...] con nuevos comercios. Pero resulta que se ha convertido en una nueva zona de juego, de timba y nada más", "...el hotel es una hermosa imagen, pero mucho movimiento no se ve. No hay un progreso; por el contrario, hay muchísimos locales cerrados" ${ }^{\prime \prime}$.

67 Diario La Gaceta, 2013. 
FIGURA 3. SECUENCIA FOTOGRÁFICA (DE IZO. A DER.) DEL EX MERCADO DE ABASTO: MERCADO ORIGINAL, SU PROCESO DE DEMOLICIÓN, NUEVO PROYECTO COMERCIAL

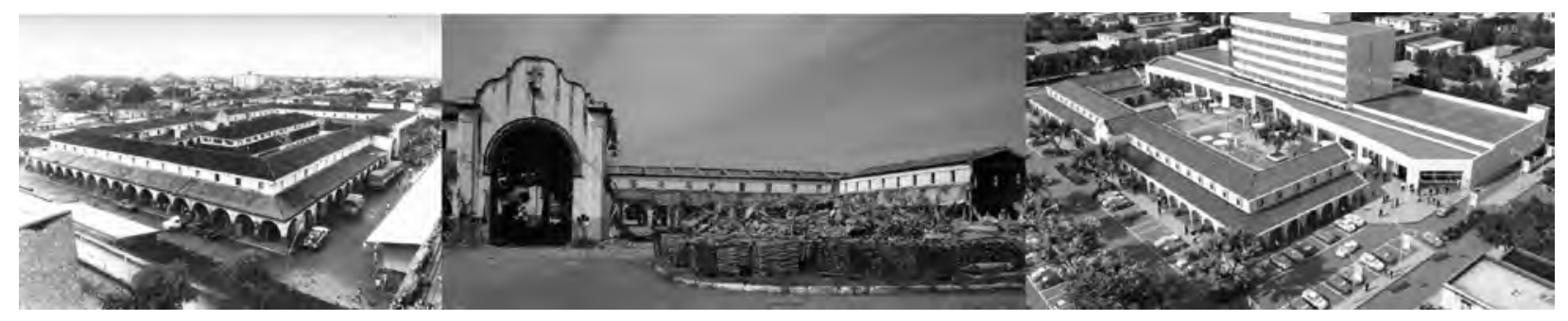

Fuente. Archivo fotográfico Diario La Gaceta (izquierda y centro) y Revista Contexto (derecha), 2011.

\section{CAMBIOS EN EL USO DEL SUELO DESDE UN ENFOQUE FUNCIONAL}

En este apartado se analizan, desde una perspectiva funcional, los cambios en el uso del suelo de ambos mercados y sus alrededores, con el fin de identificar y caracterizar las transformaciones urbanas en el transcurso de los procesos bajo estudio.

Tal como se expone en la figura 2 y en la tabla 2 , en la actualidad las funciones predominantes en la zona del ex Mercado de Abasto son la comercial y residencial. Los comercios, dedicados principalmente a la venta mayorista de comestibles y de repuestos de autos y motos, ocupan el 55,1\% de los edificios, sin embargo el 44,4\% de los mismos se encuentran cerrados en forma permanente. Las viviendas abarcan el 38,8\% de los lotes existentes, no obstante el 84,3\% de ellas están desocupadas. El elevado porcentaje de viviendas y comercios desocupados, abandonados y/o en alquiler da cuenta del impacto negativo que hasta la fecha tuvo el proceso de gentrificación. Ante las actividades de renovación urbana implementadas y el consecuente aumento del costo de vida, vecinos y comerciantes se ven obligados a abandonar el área. Esta situación, a su vez, es aprovechada por actores privados para introducir nuevas actividades compatibles con el actual proyecto de revitalización que se está ejecutando (Figura 3).

En los alrededores del Mercado del Norte, la situación es diferente, las dificultades para implementar el proyecto de renovación urbana permitieron la continuidad de las actividades tradicionales en la zona. La función principal es la comercial que abarca el 80,4\% de los locales disponibles. Está constituida por una multiplicidad de pequeños y medianos negocios dedicados principalmente a la 
FIGURA 4. USO DEL SUELO EN EL ÁREA DE INFLUENCIA DEL MERCADO DEL NORTE

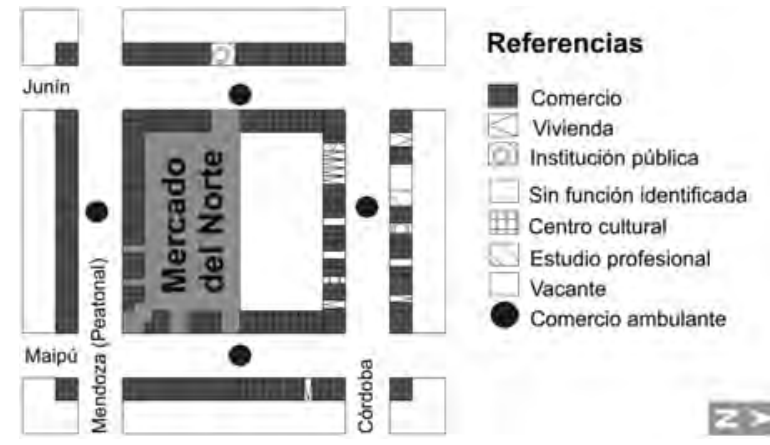

Fuente. Trabajo de campo de las autoras, 2013
TABLA 3. USO DEL SUELO EN EL ÁREA DE INFLUENCIA DEL MERCADO DEL NORTE

\begin{tabular}{lll} 
& Total absoluto & Total en \% \\
\hline Vivienda & $\mathbf{2 8}$ & $\mathbf{1 5 , 2}$ \\
\hline en uso & 28 & 15,2 \\
\hline Comercios & $\mathbf{1 4 8}$ & $\mathbf{8 0 , 4}$ \\
\hline en uso & 148 & 80,4 \\
\hline Edificios público-privados & $\mathbf{5}$ & $\mathbf{2 , 7}$ \\
\hline institución pública & 2 & 1,1 \\
\hline centro cultural & 1 & 0,5 \\
\hline estudio profesional & 2 & 1,1 \\
\hline Espacios disponibles & $\mathbf{3}$ & $\mathbf{1 , 6}$ \\
\hline vacantes & 3 & 1,6 \\
\hline Total & $\mathbf{1 8 4}$ & $\mathbf{1 0 0}$ \\
\hline
\end{tabular}

Fuente. Trabajo de campo de las autoras, 2013.

FIGURA 5. SECUENCIA FOTOGRÁFICA (DE IZO. A DER.) DEL MERCADO DEL NORTE: MERCADO ORIGINAL, DINÁMICA DE FUNCIONAMIENTO INTERNA, PROTESTAS DE TRABAJADORES

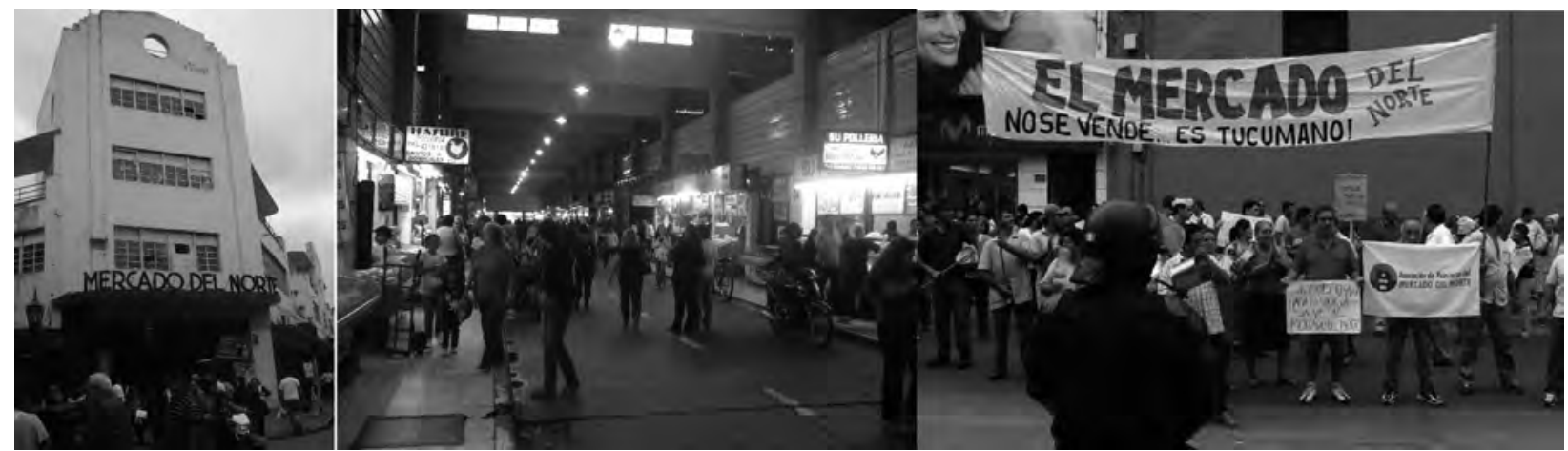

Fuente. Relevamiento de las autoras (izquierda y centro) y Tucumán Hoy (derecha), 2009. 
TABLA 4. COMERCIO INFORMAL INSTALADO SOBRE LAS CALLES LATERALES DEL MERCADO DEL NORTE

\begin{tabular}{lll} 
& Total absoluto & Total en \% \\
\hline Polirubro & 38 & 80,9 \\
\hline Verduras & 6 & 12,8 \\
\hline Floristas & 2 & 4,3 \\
\hline Revistas y diarios & 1 & 2,1 \\
\hline Total & 47 & 100 \\
\hline
\end{tabular}

Fuente. Trabajo de campo de las autoras, 2013.

venta de indumentaria, marroquinería y librería y destinados, sobre todo, a usuarios con poder adquisitivo medio y medio-bajo. Las casas de familia, en cambio, al ser edificios en altura, ocupan solamente el 15,2\% del espacio disponible ${ }^{68}$. Estos edificios sustituyeron las viviendas y/o comercios de una sola planta con el objetivo de densificar la zona. El porcentaje de espacios vacantes es despreciable lo cual indica una dinámica de uso pleno de la zona (Figuras 4 y 5, y Tabla 3).

Por otra parte, es destacable la presencia de vendedores ambulantes en todas las calles que rodean a este mercado. Su participación en las actividades comerciales informales del área contribuye a

68 Las viviendas han sido registradas en relación al Factor de Ocupación Total (FOT) que es el coeficiente que determina el aprovechamiento total del lote en relación a la superficie final construida. Si bien los lotes destinados a vivienda abarcan solamente el $4,9 \%$ del total; su incidencia asciende a $15,2 \%$ ya que se multiplica cada edificio por su cantidad de pisos.

\section{TABLA 5. ESTADO ACTUAL DE LOS PUESTOS AL INTERIOR DEL MERCADO DEL NORTE70}

\begin{tabular}{lllll} 
Sectores & $\begin{array}{l}\text { Puestos } \\
\text { abiertos }\end{array}$ & $\begin{array}{l}\text { Puestos } \\
\text { cerrados }\end{array}$ & $\begin{array}{l}\text { Puestos } \\
\text { demolidos }\end{array}$ & Total \\
pasillo 1 & 38 & 3 & 0 & 41 \\
\hline pasillo 2 & 12 & 1 & 4 & 17 \\
\hline pasillo 3 & 9 & 2 & 9 & 20 \\
\hline pasillo 4 & 12 & 3 & 1 & 16 \\
\hline pasillo 5 & 12 & 5 & 3 & 20 \\
\hline Total absoluto & $\mathbf{8 3}$ & $\mathbf{1 4}$ & $\mathbf{1 7}$ & $\mathbf{1 1 4}$ \\
\hline Total en \% & $\mathbf{7 2 , 8}$ & $\mathbf{1 2 , 3}$ & $\mathbf{1 4 , 9}$ & $\mathbf{1 0 0}$ \\
\hline
\end{tabular}

Fuente. Trabajo de campo de las autoras, 2013

la creación de un paisaje urbano popular que diferencia a la zona de otros sectores del CBD y del resto de la ciudad. El 80,9\% de los vendedores registrados, comercializan juguetes, útiles escolares y películas, entre otros productos, los cuales han sido reunidos bajo la categoría polirubro ${ }^{69}$. De los restantes aquellos que ofrecen frutas y verduras de estación (12,8\%) dependen, por lo general, de locales instalados en el interior del mercado que encuentran en este sistema de venta paralelo, otra

69 Es pertinente destacar que la oferta comercial de los vendedores ambulantes varía de acuerdo con la época del año.

revista invi № 81 / Agosto 2014 / Volumen № 29: 157-191 181 
TABLA 6. PRESENCIA DE LAS PRINCIPALES CARACTERÍSTICAS DE LA GENTRIFICACIÓN EN LOS CASOS DE ESTUDIO

\begin{tabular}{|c|c|c|c|c|}
\hline $\begin{array}{l}\text { CARACTERISTIICAS DE } \\
\text { LA GENTRIFICACIÓN }\end{array}$ & MERCADO DE ABASTO & PRESENCIA & MERCADO DEL NORTE & PRESENCIA \\
\hline Cercanía al CBD & Exento & Sí & Incluido & Sí \\
\hline $\begin{array}{l}\text { Servicios de infraes- } \\
\text { tructura proveniente de } \\
\text { red pública }\end{array}$ & $\begin{array}{l}\text { El mercado y su entorno inme- } \\
\text { diato cuentan con infraestruc- } \\
\text { tura de servicios completa }\end{array}$ & sí & $\begin{array}{l}\text { El mercado y su entorno inme- } \\
\text { diato cuentan con infraestruc- } \\
\text { tura de servicios completa }\end{array}$ & sí \\
\hline $\begin{array}{l}\text { Imagen urbana conso- } \\
\text { lidada. Lugares asocia- } \\
\text { dos a la memoria }\end{array}$ & $\begin{array}{l}\text { Edificio protegido por la ley } \\
\text { provincial } 7535 \text { que lo declara } \\
\text { como patrimonio cultural, } \\
\text { histórico y arquitectónico de } \\
\text { Tucumán. Tejido urbano, espa- } \\
\text { cios públicos y edificaciones } \\
\text { característicos de un momen- } \\
\text { to histórico de la ciudad }\end{array}$ & sí & $\begin{array}{l}\text { Edificio protegido por la ley } \\
\text { provincial } 7535 \text { que lo declara } \\
\text { como patrimonio cultural, } \\
\text { histórico y arquitectónico de } \\
\text { Tucumán. Tejido urbano, espa- } \\
\text { cios públicos y edificaciones } \\
\text { característicos de un momen- } \\
\text { to histórico de la ciudad }\end{array}$ & sí \\
\hline Áreas deterioradas & $\begin{array}{l}\text { El edificio está abandonado y } \\
\text { presenta niveles alarmantes } \\
\text { de deterioro }\end{array}$ & sí & $\begin{array}{l}\text { El edificio presenta niveles } \\
\text { alarmantes de deterioro }\end{array}$ & $\begin{array}{l}\text { Edificio en } \\
\text { riesgo }\end{array}$ \\
\hline $\begin{array}{l}\text { Inversión privada de } \\
\text { capital }\end{array}$ & $\begin{array}{l}\text { Desarrolla y ejecuta Vizora, } \\
\text { Desarrollos Inmobiliarios }\end{array}$ & sí & $\begin{array}{l}\text { Desarrolla Grupo empresarial } \\
\text { Inversiones y Representacio- } \\
\text { nes S. A. (IRSA) }\end{array}$ & sí \\
\hline $\begin{array}{l}\text { Cambios en el uso } \\
\text { funcional }\end{array}$ & $\begin{array}{l}\text { Construcción de un hotel de } \\
\text { lujo y casino. Se prevé la in- } \\
\text { corporación de negocios de } \\
\text { alta gama }\end{array}$ & sí & $\begin{array}{l}\text { Se preveé desarrollar un cen- } \\
\text { tro comercial tipo shopping } \\
\text { center }\end{array}$ & Proyecto \\
\hline $\begin{array}{l}\text { Desplazamiento directo } \\
\text { o indirecto de la pobla- } \\
\text { ción local }\end{array}$ & $\begin{array}{l}\text { Condiciones aptas para la } \\
\text { sustitución } 84,3 \% \text { de viviendas } \\
\text { abandonadas } 44,4 \% \text { de comer- } \\
\text { cios abandonados }\end{array}$ & $\begin{array}{l}\text { En proceso } \\
\text { (inacabado) }\end{array}$ & $\begin{array}{l}\text { Intensos procesos de resisten- } \\
\text { cia por parte de trabajadores } \\
\text { y usuarios } 27,2 \% \text { de puestos } \\
\text { desocupados }\end{array}$ & $\begin{array}{l}\text { En proceso } \\
\text { (inacabado) }\end{array}$ \\
\hline
\end{tabular}

Fuente. Zukin, 1996; Bataller, 2000; Améndola, 2000; Bomba, Caminos, Casares y Di Lullo, 2007; Trabajo de campo de las autoras, 2013. 
TABLA 7. CARACTERÍSTICAS DE LA GENTRIFICACIÓN SEGÚN LAS FASES DE DESARROLLO ELABORADAS

\begin{tabular}{|c|c|c|c|c|c|c|c|}
\hline & FASE 1 & FASE 2 & & FASE 3 & & SE 4 & FASE 5 \\
\hline & $\begin{array}{l}\text { Deterioro } \\
\text { urbano }\end{array}$ & $\begin{array}{l}\text { Formulación de pro- } \\
\text { yectos comerciales }\end{array}$ & Impacto & Transición & $\begin{array}{l}\text { Materializa- } \\
\text { ción de los } \\
\text { cambios }\end{array}$ & Impacto & $\begin{array}{l}\text { Funciona- } \\
\text { miento y } \\
\text { adaptación } \\
\text { del entorno }\end{array}$ \\
\hline 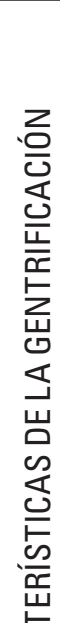 & $\begin{array}{l}\text { Se identifica } \\
\text { el área como } \\
\text { un sector } \\
\text { degradado, } \\
\text { con potencial } \\
\text { comercial. }\end{array}$ & $\begin{array}{l}\text { Las iniciativas de } \\
\text { transformación pro- } \\
\text { vienen de intereses } \\
\text { público-privados. El } \\
\text { proyecto de moder- } \\
\text { nización reproduce } \\
\text { una imagen urbana } \\
\text { y arquitectónica } \\
\text { dominante. Busca } \\
\text { sustituir la activi- } \\
\text { dad tradicional del } \\
\text { área. Su elabora- } \\
\text { ción no incluye a la } \\
\text { comunidad directa- } \\
\text { mente afectada. }\end{array}$ & $\begin{array}{l}\text { Varía según } \\
\text { diferentes } \\
\text { factores: 1) } \\
\text { apropiación } \\
\text { de los veci- } \\
\text { nos-usuarios } \\
\text { de la zona; } \\
\text { 2) grado de } \\
\text { integración } \\
\text { vecinal; 3) } \\
\text { manejo de } \\
\text { información }\end{array}$ & $\begin{array}{l}\text { Se intro- } \\
\text { ducen } \\
\text { actividades } \\
\text { comerciales } \\
\text { temporales } \\
\text { que impac- } \\
\text { tan en las } \\
\text { actividades } \\
\text { tradicionales } \\
\text { generando } \\
\text { incompa- } \\
\text { tibilidad y } \\
\text { abandono }\end{array}$ & $\begin{array}{l}\text { Demolición } \\
\text { e inicio de } \\
\text { las obras. } \\
\text { Desmantela- } \\
\text { miento defi- } \\
\text { nitivo de las } \\
\text { actividades } \\
\text { y espacios } \\
\text { tradicionales }\end{array}$ & $\begin{array}{l}\text { Implantación } \\
\text { de cambios } \\
\text { irreversibles. } \\
\text { El proceso } \\
\text { de gentri- } \\
\text { ficación se } \\
\text { encuentra } \\
\text { prácti- } \\
\text { camente } \\
\text { consolidado }\end{array}$ & $\begin{array}{l}\text { Inauguración } \\
\text { de las nuevas } \\
\text { instalaciones. } \\
\text { Isla de } \\
\text { consumo. } \\
\text { Incertidumbre } \\
\text { de vecinos, } \\
\text { comer- } \\
\text { ciantes y } \\
\text { trabajadores } \\
\text { respecto del } \\
\text { futuro }\end{array}$ \\
\hline 遮 & $\begin{array}{l}\text { El Estado no d } \\
\text { mantenimient } \\
\text { de la zona }\end{array}$ & $\begin{array}{l}\text { estina fondos para el } \\
\text { o y/o mejoramiento }\end{array}$ & $\begin{array}{l}\text { Posibilidad de } \\
\text { al impulso ge } \\
\text { tanto se lleva } \\
\text { tividades de } \\
\text { contra del nu }\end{array}$ & $\begin{array}{l}\text { poner freno } \\
\text { trificador, en } \\
\text { a cabo ac- } \\
\text { sistencia en } \\
\text { vo proyecto }\end{array}$ & & & \\
\hline & $\begin{array}{l}\text { SO DE GEN } 7 \\
0\end{array}$ & RIFICACIÓN EN & & & & & \\
\hline
\end{tabular}

Fuente. Trabajo de campo de las autoras. 2013. 
fuente de ingreso económico al captar clientes que no suelen entrar al mercado (Tabla 4).

Ahora bien, en el interior del mercado, la deteriorada condición edilicia general y de sus puestos junto con el número considerable de locales vacíos, reflejan la inestabilidad laboral de los trabajadores del mercado. Durante el trabajo de campo se constató que de los 250 puestos creados cuando se inauguró el edificio, sólo permanecen en pie 114. De ellos el $72,8 \%$ se encuentra funcionando mientras que los restantes, es decir la tercera parte aproximadamente, están cerrados o fueron demolidos. Estas tareas de demolición están a cargo del Municipio y reflejan el interés por evitar que dichos puestos sean re-ocupados (Tabla 5). Como ya se señaló, la falta de negociaciones y acuerdos entre el Municipio capitalino y los puesteros propician su gradual deterioro y dan lugar al avance de un proceso de renovación urbana que excluye a los trabajadores tradicionales de la zona.

\section{Síntesis de los resultados}

Este aparatado tiene por objetivo resaltar de manera sintética los principales aportes de esta investigación. En este sentido la Tabla 6, resume en

184 revista invi № 81 / Agosto 2014 / Volumen № 29: 157-191 forma esquemática las principales características de la gentrificación y explica cómo se desarrollan en ambos casos de estudio. En el caso del Mercado de Abasto la presencia de estas características es significativamente evidente en tanto el proceso de gentrificación se encuentra prácticamente acabado. De hecho la última característica, es decir el desplazamiento directo o indirecto de la población local, se encuentra en pleno proceso. En cambio, en el Mercado del Norte estas características también están presentes pero su desarrollo es más lento. Si bien el edificio está deteriorado, continúa actuando como mercado central, motivo por el cual aún no se ha producido el cambio en el uso funcional. Asimismo, el desplazamiento de la población local es menos intenso que en el caso anterior.

Como ya se explicó en apartados anteriores, la trayectoria por la que atravesaron ambos mercados durante el proceso de gentrificación está compuesta por el desarrollo de cinco fases. Ahora bien, la Tabla 7, tiene por objetivo sintetizar y caracterizar dichas fases en tanto podrían ser susceptibles de aplicarse en ciudades con atributos similares. En estas fases, es posible advertir el accionar del Estado, de las empresas privadas participantes y de la comunidad (representada por vecinos, usuarios y trabajadores del mercado). Abarcan desde

70 El edificio del Mercado del Norte tiene una distribución cuadricular, con un total de cinco pasillo, tres en sentido este-oeste y dos en sentido norte sur.

ARTíCULO: Procesos de gentrificación y contragentrificación. Los mercados de Abasto y de Norte en el Gran San Miguel de Tucumán (noroeste argentino) / Paula Luciana Boldrini, 
el deterioro edilicio de los edificios objeto de la gentrificación, hasta la puesta en funcionamiento del nuevo proyecto y su proceso de adaptación en el entorno que lo rodea. Asimismo las fases dos y cuatro han sido subdividas en tanto la formulación de los nuevo proyectos y la materialización de los cambios, respectivamente, provocan un determinado impacto socio-espacial que es preciso analizar. De este modo para que un proceso de gentrificación se concrete es preciso que transite por las cinco fases, de lo contrario se encontrará en curso o bien interrumpido.

\section{Reflexión final}

Los procesos de gentrificación y contragentrificación ocurridos en el aglomerado GSMT presentan características similares a aquellos descritos para las grandes ciudades de América Latina. Teniendo en cuenta el carácter de ciudad intermedia del aglomerado y su devenir geohistórico particular, estos procesos adoptan rasgos particulares al circunscribirse a áreas urbanas puntuales que contienen edificios emblemáticos como el Mercado de Abasto y el Mercado del Norte y sus respectivos entornos.

Los cambios inherentes a los procesos de gentrificación propuestos aparecen encubiertos como procesos de renovación o revitalización urbana. Se utiliza la propaganda comercial y política haciendo hincapié en los beneficios de sustituir una actividad de baja jerarquía en relación al modelo de ciudad competitiva por otra que, por el contrario, se presenta como símbolo de progreso y atractivo turístico. Emprendimientos explotados por empresas monopólicas que redundan en un proceso urbano y productivo de carácter completamente exógeno y excluyente de las necesidades productivas y habitacionales endógenas.

Los nuevos emprendimientos tienen por objetivo transformar la actividad tradicional dominante de los mercados y su área de influencia inmediata al implantar proyectos comerciales de gran envergadura destinados a un público con poder adquisitivo medio alto y alto. Mediante estos cambios se desplaza, de manera directa o indirecta, al grupo social que vivía y trabajaba en la zona. El proceso gentrificador se ciñe al interés público-privado de las partes que lo llevan adelante, es decir el Estado Municipal en concordancia con la empresa privada ejecutora. De este modo se evidencia un manejo claramente especulativo de las áreas afectadas con el fin de debilitar las funciones urbanas tradicionales, y construir una especie de tabula rasa que contribuya a la re funcionalización socio-espacial de los sectores afectados.

El derrotero por el que atravesaron ambos mercados durante el proceso de gentrificación está compuesto por el desarrollo de cinco fases interrelacionadas. En el caso del Mercado de Abasto se 
concretaron todas las fases. Las transformaciones urbanas comenzaron con la detección de un espacio urbano deteriorado y finalizaron con la reciente inauguración de las instalaciones comerciales. De este modo presenciamos un proceso de gentrificación prácticamente concluido e irreversible. Por el contrario, en el caso del Mercado del Norte, sólo se concretaron las tres primeras fases. Trabajadores y vecinos, con el apoyo de otros sectores de la comunidad, se organizaron para llevar adelante medidas de resistencia en contra del proceso gentrificador poniendo en marcha una dinámica contragentrificadora aún vigente. Por lo tanto el establecimiento de las primeras fases no implica que la gentrificación se cumpla de manera plena ya que puede planearse, interrumpirse o concretarse. Estas fases integran un modelo de análisis urbano susceptible de ser aplicado en ciudades con atributos similares.

Finalmente, la gentrificación en el aglomerado GSMT, es un tipo de renovación o rehabilitación urbana que deja sus huellas en la ciudad actual, profundizando el carácter excluyente y fragmentado que debilita la integración comunitaria y atenta contra una identidad urbana construida históricamente. Por el contrario, la contragentrificación posibilitó la gestación de acciones colectivas que promueven espacios de resistencia en pos del mantenimiento de las actividades comerciales tradicionales del área. El ejercicio de estas acciones comunitarias está vinculado a una concepción de la tierra como bien de uso, dado que la participación colectiva garantiza, en gran medida, la prevalencia del interés común en la producción de la ciudad sobre los intereses sectoriales. Estas experiencias promueven la discusión sobre un modelo de ciudad impuesto, versus un modelo de ciudad construido colectivamente, en tanto puedan traspasar la barrera de lo meramente operativo y casuístico, para convertirse en procesos repolitizantes.

Las transformaciones socio-espaciales deberían promover el ejercicio participativo, para finalmente implicar mejoras contundentes e integradoras en el desarrollo local y urbano, mediante el ejercicio democrático.

\section{Bibliografía}

ÁLVAREZ, Felipe. Gentrificación ia la chilena? [En línea]. Plataforma urbana. 2010. [Fecha de consulta: 12 marzo 2013]. Disponible en: http:// www.plataformaurbana.cl/archive/2010/07/12/ gentrificacion-\%C2\%BFa-la-chilena/

AMÉNDOLA, Giandoménico. La ciudad moderna. Magia y miedo de la metrópolis contemporánea. $2^{2}$ ed. Madrid, España, Ediciones Celeste. 2000. 300 p. ISBN 84-8213239-2.

BATALLER, María Alba. El estudio de la gentrificación. [En línea]. Biblio $3 \mathrm{~W}$, revista bibliográfica de geografía y ciencias sociales. (228), mayo 2000. ISSN 1138-9796. Disponible en: http://www.ub.edu/ geocrit/b3w-228.htm 
BAYARD0, Rubens, comp y LACARRIEU, Mónica, comp. La dinámica global/local. Cultura y comunicación: nuevos desafíos. Buenos Aires, Argentina, Ciccus. 1999. 294 p. ISBN 987-9355-01-6.

BOMBA, Héctor; CAMINOS, Rafael, CASARES, Marta y DI LULLO, Raúl. Perspectivas del medio ambiente urbano. Informe GEO, San Miguel de Tucumán. [En línea]. México, Programa de las Naciones Unidas para el Medio Ambiente. 2007. [Fecha de consulta: 3 marzo 2013]. Disponible en: http://www.pnuma.org/deatl/ pdf/2007GEOSanMigueldeTucumn.pdf

BORJA, Jordi; CASTELLS, Manuel. Local y global. La gestión de las ciudades en la era de la información. México, Taurus pensamiento. 1998. 253p. ISBN 9788430602698.

CARBAJAL, Rodrigo. Transformaciones socio económicas y urbanas en Palermo. Revista Argentina de Sociología. (1): 94-109, 2003. ISSN 1667-9261.

CICCOLELLA, Pablo. Globalización y dualización en la región metropolitana de Buenos Aires. Grandes inversiones y reestructuración socio-territorial en los años 90. [En línea]. EURE. 25(76): 5-27, diciembre 1999. ISSN 0250-7161. Disponible en: http:// dx.doi.org/10.4067/S0250-71611999007600001

- Revisitando la metrópolis latinoamericana más allá de la globalización. Revista Iberoamericana de Urbanismo. (8): 9-21, 2012. ISSN 2013-6242.

DI VIRGILIO, Mercedes; LANZETTA, Máximo; REDOND0, Adriana y RODRÍGUEZ, María Carla. Procesos de renovación urbana en Buenos
Aires: percepciones de habitantes de La Boca. [En línea]. Revista Mundo Urbano. (2), 2000. ISSN 1515-8373. Disponible en: http://www.mundourbano.unq.edu.ar/index.php/ano-2000/38 numero-2--junio/39-2-los-procesos-de-renovacion-urbana-en-buenos-aires-percepciones-dehabitantes-de-la-boca

DÍAZ PARRA, Ibán. Gentrificación y clase social. La producción del gentrificador. [En línea]. La ciudad viva. 2004. [Fecha de consulta: 12 marzo 2013]. Disponible en: http://www.laciudadviva. org/opencms/export/sites/laciudadviva/recursos/documentos/Gentrificacion_y_clase_social._La_Produccion_del_gentrificador.pdf157d408337ee53fa4bc189b4a7cd96ea.pdf

FÉLIZ, Mariano. ¿Neo-desarrollismo: más allá del neoliberalismo? Desarrollo y crisis capitalista en Argentina desde los 90. [En línea]. Revista Theomai: Estudios Críticos sobre Sociedad y Desarrollo. (23): 72-86, 2011. ISSN 1515-6443. Disponible en: http://revista-theomai.unq.edu.ar/NUMERO $\% 20$ 23/5_Feliz_\%2072-86.pdf

GARCÍA HERRERA, Luz Marina. Elitización: propuesta en español para el término gentrificación. [En línea]. Biblio 3W, revista Bibliográfica de Geografía y Ciencias Sociales. 6(332), 2001. ISSN 1138-9796. Disponible en: http://www.ub.edu/geocrit/b3w332.htm

GÓMEZ LÓPEZ, Claudia; CUOZZO, Rosa Lina y BOLDRINI, Paula. Expansión urbana y desigualdades socio-territoriales en el Área Metropolitana de Tucumán. Argentina. En: Coloquio de 
Transformaciones Territoriales $\left(9^{\circ}, 2012\right.$, Tucumán, Argentina). Coloquio internacional de transformaciones territoriales: Huellas e incertidumbres en los procesos de desarrollo territorial. Argentina, Universidad Nacional de Tucumán, Facultad de Arquitectura y Urbanismo. 2012

GREGORIO, Roberto de. La casa criolla popularmente llamada la casa chorizo. Buenos Aires, Argentina, Nobuko. 2006

GUBER, Rosana. El salvaje metropolitano. Buenos Aires, Argentina, Legasa. 2009. 328 p. ISBN 9501227197.

HARVEY, David. La condición de la posmodernidad. Investigación sobre los orígenes del cambio cultural. Buenos Aires, Argentina, Amorrortu. 1998. 406 p. ISBN 950-518-652-5.

INSTITUTO Nacional de Estadística y Censo (INDEC). Encuesta permanente de hogares (EPH). [En línea]. Instituto Nacional de estadística y Censo. Junio 2012. [Fecha de consulta: 1 marzo 2013]. Disponible en: http://www.indec.gov.ar/

JANOSCHKA, Michael. El nuevo modelo de la ciudad latinoamericana: fragmentación y privatización. [En línea]. Eure. 28(85): 11-20, 2002. ISSN 02507161. Disponible en: http://dx.doi.org/10.4067/ S0250-71612002008500002

- Geografías urbanas en la era del neoliberalismo. Una conceptualización de la resistencia local a través de la participación y la ciudadanía urbana. [En línea]. Investigaciones Geográficas. Boletín del Instituto de Geografía. (76): 118-132,
2011. ISSN 0188-4611. Disponible en: http:// www.journals.unam.mx/index.php/rig/article/ view/29879/27778

JANOSCHKA, Michael y CASGRAIN, Antoine. Urbanismo neoliberal y gentrificación en Santiago de Chile. Diálogos entre teoría urbana y reivindicación vecinal. [En línea]. Documento de estudio Polar. Movimiento de Pobladores en Lucha. 2010. [Fecha de consulta: 12 marzo 2013]. Disponible en: http://penalolenvotano.bligoo.cl/media/ users/17/863351/files/167929/MPL_Gentrificacion.pdf

JORDAN, Ricardo, comp. y SIMIONI, Daniela, comp. Ciudades intermedias de América Latina y El Caribe: propuestas para la gestión urbana. [En línea]. Comisión Económica para América Latina y El Caribe. 1998. Disponible en: www.eclac. org/publicaciones/xml/7/4497/lcl1117.pdf

KATZ, Claudio. El rediseño de América Latina: ALCA, MERCOSUR y ALBA. Buenos Aires, Ediciones Luxemburg. 2006. 144 p. ISBN 987-21734-5-6.

LEFEBVRE, Henri. El derecho a la ciudad. $2^{\mathrm{a}}$ ed. Barcelona, España, Península. 1973. 170 p. ISBN 84-297-0916-9.

LESS, Loretta; SLATER, Tom y WYLY, Elvin. Gentrification. New York, Estados Unidos, Routledge. 2007. 308 p. ISBN 978-0-415-95036-7.

LIENUR, Jorge. Arquitectura en la Argentina del siglo XX. La construcción de la modernidad. Buenos Aires, Argentina, Fondo Nacional de las Artes. 2001. 445 p. ISBN: 978-950-9807-66-2.

ARTíCULO: Procesos de gentrificación y contragentrificación. Los mercados de Abasto y de Norte en el Gran San Miguel de Tucumán (noroeste argentino) / Paula Luciana Boldrini, 
MALIZIA, Matilde y BOLDRINI, Paula. Las lógicas de ocupación del espacio urbano. Un estudio de realidades contrapuestas. El caso de las urbanizaciones cerradas y villas miseria en Yerba Buena, Gran San Miguel de Tucumán. Cuadernos de Humanidades. ISSN 0327-1471. En prensa.

MALIZIA, Matilde y PAOLASSO, Pablo. Countries y barrios privados en Yerba Buena, Gran San Miguel de Tucumán, Argentina: nuevas formas de expansión urbana. Estudios Demográficos y Urbanos. 24(3): 583-614, 2009. ISSN 0186-7210.

MALIZIA, Matilde. Countries y barrios privados en el Gran San Miguel de Tucumán. Efectos y contrastes sociales. Argentina, Facultad de Filosofía y Letras, Universidad Nacional de Tucumán. 2011. Tesis doctoral.

MATTOS, Carlos de. Modernización capitalista y revolución urbana en América Latina: cinco tendencias genéricas. En: Brand, Peter, comp. La ciudad latinoamericana en el siglo XXI. Globalización, neoliberalismo, planeación. Bogotá, Colombia, Universidad Nacional de Colombia. 2009. p. 3782. ISBN 978-958-728-018-0.

MERTINS, Gunter. Ciudades nuevas - ciudades privadas. Población E Sociedad. (10/11): 183-192, 2003/2004. ISSN 0328-3445.

MERTINS, Gunter. Transformaciones recientes en las metrópolis Latinoamericanas y repercusiones espaciales. En Luzón, José, coord.; Stardel, Cristoph, coord.. y Borges, César coord. Transformaciones regionales y urbanas en Europa y América
Latina. Barcelona, España, Universitat de Barcelona. 2003. p. 191-207. ISBN 84-475-2757-3.

PAOLASSO, Pablo; MALIZIA Matilde y LONGHI, Fernando. Vulnerabilidad y segregación socio-espacial en el Gran San Miguel de Tucumán. En: Vergara Durán, Ricardo. Vulnerabilidad en Grandes Ciudades de América Latina. 2011. p. 50-71. ISBN 978-958-741-121-8.

PORTES, Alejandro; ROBERTS, Bryan; GRIMSON, Alejandro y ALIAGA, Lissette. Ciudades latinoamericanas. Un análisis comparativo en el umbral del nuevo siglo. Buenos Aires, Argentina. 2005. 556 p. ISBN 9875740519

PRÉVÔT Schapira, Marie-France. Fragmentación espacial y social: conceptos y realidades. Perfiles Latinoamericanos. (19): 33-56. 2002. ISSN 0188-7653.

SABATINI, Francisco; Sarella Robles; María y Vásquez, Héctor. Gentrificación sin expulsión, o la ciudad latinoamericana en una encrucijada histórica. Revista 180. (24): 18-25. 2009. ISSN 0718-669X.

SABATINI, Francisco. La segregación, los guetos y la integración social urbana: mitos y claves. [En línea]. Eure. 34(103): 5-26. 2008. ISSN 02507161. Disponible en: http://dx.doi.org/10.4067/ S0250-71612008000300001

SALINAS ARREORTUA, Luis Alberto. Gentrificación en la ciudad latinoamericana: el caso de Buenos Aires y Ciudad de México. [En línea]. Geographos. (44): 281-304. 2013. ISSN 2173-1276.

revista invi № 81 / Agosto 2014 / Volumen № 29: 157-191 189 
Disponible en: http://dx.doi.org/10.14198/ GEOGRA2013.4.44

SASSEN, Saskia. Una sociología de la globalización. Buenos Aires, Argentina. 2007. 323 p. ISBN 978-84-935432-6-6.

SAUER, Carl. Foreword to historical geography. [En línea]. Annals of the Association of American Geographers. 31(1): 1- 24, 1941. ISSN: 1467-8306. Disponible en: http://dx.doi. org/10.1080/00045604109357211

SMITH, Neil. ¿Ciudades después del neoliberalismo? En: SMITH, Neil et al. Después del neoliberalismo: ciudades y caos sistémico. 2008. p. 9-30. ISBN 978-84-490-2598-3.

SPDUA. San Miguel de Tucumán, Ciudad Histórica. Tucumán: Municipalidad de San Miguel de Tucumán. Secretaría de Planificación y Desarrollo Urbanístico Ambiental. Tucumán, Argentina. 2002.

SVAMPA, Maristella. Cambio de época. Movimientos sociales y poder político. Buenos Aires, Siglo XXI, CLACSO. 2008. 132 p. ISBN 9789876290524

TAYLOR, Steve y BOGDAN, Robert. Introducción a los métodos cualitativos de investigación. La búsqueda de significados. Buenos Aires, Argentina, Paidos. 1990. 343 p. ISBN 8475098169.

TELLA, Guillermo. Rupturas y continuidades en el sistema de centralidades de Buenos Aires. En: WELCH GUERRA, Max, ed. Buenos Aires a la deriva. Transformaciones urbanas recientes. 2005. p. 29-73. ISBN 950786461X.

190 revista invi № 81 / Agosto 2014 / Volumen № 29: 157-191
URBINA GONZÁLEZ, Amparo. El centro histórico de Bogotá "de puertas para adentro": ¿el deterioro del patrimonio al servicio de la gentrificación? [En línea]. Cuadernos de Vivienda y Urbanismo. 5(9): $46-$ 69. 2012. ISSN 2027-2103. Disponible en: http:// revistas.javeriana.edu.co/index.php/cvyu/article/ view/5389/4425

VAPÑARSKY, César. Crecimiento urbano diferencial y migraciones en la Argentina: cambios de tendencias desde 1970. Estudios migratorios latinoamericanos. 9(27): 225-260, 1994. ISSN 0326-7458.

- Primacía y macrocefalia en la Argentina: la transformación del sistema de asentamiento humano desde 1950. Desarrollo económico. 35(138): 227254, 1995. ISSN 0046-001X.

YUNI, José y URBANO, Claudio. Recursos metodológicos para la preparación de proyectos de investigación. Córdoba, Argentina, Brujas. 2003. v. 2, 114 p. ISBN 9875910201.

ZUKIN, Sharon. Paisagens urbanas pos modernas: mapeando cultura y poder. Revista do Patrimônio Histórico e Artístico Nacional. (24): 205-219. 1996. ISSN 0102-2571.

\section{Fuentes consultadas}

Archivo fotográfico Diario La Gaceta.

El ex Abasto pide paciencia: cambiará, pero despacio. [En línea]. Diario La Gaceta. 2012. Disponible en: http://www.lagaceta.com.ar/nota/516595/

ARTíCULO: Procesos de gentrificación y contragentrificación. Los mercados de Abasto y de Norte en el Gran San Miguel de Tucumán (noroeste argentino) / Paula Luciana Boldrini, 
ex-abasto-pide-paciencia-cambiara-pero-despacio.html?origen $=$ mlt

El inolvidable Mercado de Abasto. Aquí latía el corazón de La Ciudadela. [En línea]. Diario La Gaceta. 2012. Disponible en: http://www.lagaceta.com.ar/blogs/elarcon/482005/El-inolvidable-Mercado-de-Abasto-Aqui-latia-el-corazonde-La-Ciudadela.html

El progreso se cuece a fuego lento en el ex Abasto. [En línea]. Diario La Gaceta. 2013. Disponible en: http://www.lagaceta.com.ar/nota/543733/ ciudad/progreso-se-cuece-fuego-lento-exabasto.html
Hotel 5 estrellas y centro de convenciones en El Abasto. [En línea]. Revista Contexto. 2011. Disponible en: http://www.contexto.com.ar/nota/44879/hotel-5-estrellas-y-centro-de-convenciones-en-elabasto.html

Mercado del norte: un terreno en disputa. [En línea]. Contrapunto. 2008. Disponible en: http://prensacontrapunto.com.ar/index.php?option=com_co ntent\&task=view\&id=737\&Itemid=1

Puesteros del Mercado del Norte resistirán el inminente desalojo. [En línea]. Diario Tucumán Hoy. 2009. Disponible en: http://www.tucumanhoy. com/VerNotaCompleta.py?IDNOTA=14493 